\title{
Residential Self-Selection Effects in an Activity Time-Use Behavior Model
}

\author{
Abdul Rawoof Pinjari \\ University of South Florida \\ Dept of Civil \& Environmental Engineering \\ 4202 E. Fowler Ave., ENC 2503, Tampa, FL 33620 \\ Phone: 813-974-9671, Fax: 813-974-2957 \\ E-mail: apinjari@eng.usf.edu \\ Chandra R. Bhat* \\ The University of Texas at Austin \\ Dept of Civil, Architectural \& Environmental Engineering \\ 1 University Station C1761, Austin TX 78712-0278 \\ Phone: 512-471-4535, Fax: 512-475-8744 \\ E-mail: bhat@mail.utexas.edu \\ David A. Hensher \\ The University of Sydney \\ Institute of Transport and Logistics Studies, Faculty of Economics and Business \\ 144 Burren Street, Sydney, NSW, Australia \\ Phone: 61(2) 9351 0071, Fax: 61(2) 93510088 \\ E-mail: davidh@itls.usyd.edu.au \\ * corresponding author. \\ The research in this paper was undertaken and completed when the corresponding author was a Visiting \\ Professor at the Institute of Transport and Logistics Studies, Faculty of Economics and Business, \\ University of Sydney.
}




\begin{abstract}
This study presents a joint model system of residential location and activity time-use choices that considers a comprehensive set of activity-travel environment (ATE) variables, as well as sociodemographic variables, as determinants of individual weekday activity time-use choices. The model system takes the form of a joint mixed Multinomial Logit-Multiple DiscreteContinuous Extreme Value (MNL-MDCEV) structure that (a) accommodates differential sensitivity to the ATE attributes due to both observed and unobserved individual-related attributes, and (b) controls for the self selection of individuals into neighborhoods due to both observed and unobserved individual-related factors. The joint model system is estimated on a sample of 2793 households and individuals residing in Alameda County in the San Francisco Bay Area.

The model results indicate the significant presence of residential self-selection effects due to both observed and unobserved individual-related factors. For instance, individuals from households with more bicycles are associated with a higher preference for out-of-home physically active pure recreational travel pursuits (such as bicycling around in the neighborhood). These same individuals locate into neighborhoods with good bicycling facilities. This leads to a non-causal association between individuals' time investment in out-of-home physically active pure recreational travel and bicycling facilities in their residential neighborhoods. Thus, ignoring the effect of bicycle ownership in the time-use model, would lead to an inflated estimate of the effect of bicycling facility density on the time invested in physically active pure recreational travel. Similarly, there are significant unobserved individual factors that lead to a high preference for physically active recreational activities and also make individuals locate in areas with good bicycling facilities. When such unobserved factors were controlled by the proposed joint residential location and time-use model, the impact of bicycling facility density on out-of-home physically active recreational activities ceased to be statistically significant (from being statistically significant in the independent time-use model). These results highlight the need to control for residential self-selection effects when estimating the effects of the activity-travel environment on activity time-use choices.
\end{abstract}

Keywords: Residential location choice, residential self-selection, time-use, multiple discretecontinuous extreme value model, integrated land use-transportation modeling. 


\section{INTRODUCTION}

The primary focus of transportation planning, until the past three decades or so, was to meet long-term mobility needs by providing adequate transportation infrastructure supply. In such a mobility-centric, supply-oriented, planning process, the main role of travel demand models was to predict aggregate travel demand for long-term socio-economic scenarios, and for alternative transportation system characteristics and land-use configurations.

Over the past three decades, however, because of rapid economic growth, increasing auto dependency, accelerating urban sprawl, escalating capital costs of new infrastructure, and increasing concerns regarding air-quality deterioration and traffic congestion, the mobilitycentric, supply-oriented, focus of transportation planning has expanded to include the objectives of (a) promoting sustainable communities and urban areas by integrating transportation planning with land-use planning, and (b) addressing mobility needs and problems by managing travel demand within the available transportation supply. Consequently, and correspondingly, there has been an increasing interest in (a) land-use policies (such as mixed land-use development and transit oriented development) that attempt to modify the land-use configuration in an effort to reduce auto-oriented travel and promote other means of transportation, and (b) travel demand management strategies, such as congestion pricing, that attempt to change transportation service characteristics to influence individual travel behavior and control aggregate travel demand.

The interest in analyzing the potential of land-use and travel demand management policies to manage travel demand, in turn, has led to a shift in travel demand modeling from the statistical prediction of aggregate-level, long-term, travel demand to understanding disaggregatelevel (i.e., individual-level) behavioral responses to land-use and demand management policies. This is evidenced in the evolution of the field along two directions: (a) Integrated land-use travel demand modeling (to better understand land-use policy impacts), and (b) Activity-based travel demand modeling (to better understand demand management policy effects). Each of these two research directions are discussed in turn in the next two sections, while Section 1.3 positions the research in the current study.

\subsection{Integrated Land-use Travel Demand Modeling}

In the typical approach to travel demand modeling, land-use attributes are considered predetermined and exogenous, and are used as independent variables to explain travel behavior. Such an approach implicitly assumes a one-directional relationship between land-use and travel demand. In the past decade, there has been an increasing amount of research focused on revisiting this simplistic assumption, and considering more complex inter-relationships that may exist between land-use and travel demand. To understand these relationships, considerable research has focused on accommodating the endogeneity of long-term location choices (such as residential location and work location) with short-term travel choices through the integrated modeling of location choices and travel choices. ${ }^{1}$ This stream of research recognizes the possibility that employment, residential, and travel choices are not independent of each other,

\footnotetext{
${ }^{1}$ Such efforts date back to Lerman (1976) who estimated a joint choice model of residential location, car ownership and mode choice to work. Since then, several research efforts, including Abraham and Hunt (1997), Ben-Akiva and Bowman (1998), Eliasson and Mattsson (2000), Waddell (2006), and Salon (2006), aimed at integrated modeling of location choices and travel choices. Such models are also at the core of an integrated land use - transportation model developed by Anas and colleagues (see Anas and Duann, 1985; Anas, 1995; Anas, 1981). In addition to this work on the integrated modeling of location choices and travel choices, several studies (for example, Waddell 1993a and de Palma et al., 2005) have focused on the endogeneity of work location and/or other factors such as housing price in residential location choice models.
} 
and that individuals and households adjust with combinations of short-term travel-related and long-term location choice-related behavioral responses to land-use and transportation policies (Waddell, 2001).

Within the broader context of integrated land-use transportation modeling, a recently emerging issue is a debate whether any effect of land-use on travel demand is causal or merely associative (or some combination of the two; see Bhat and Guo, 2007, and Cao et al., 2006a). To understand this issue better, consider a land-use policy to improve bicycling facilities, with the objective of reducing automobile dependence and increasing physically active recreational pursuits. To assess the impacts of such a policy, assume that a data collection effort has been undertaken to examine the bicycling levels of individuals in neighborhoods with different levels of existing bicycling facilities. An analysis of this data may find that individuals residing in neighborhoods with good bicycling facilities pursue more bicycling-related activities. The question is whether this relationship implies that building neighborhoods with good bicycling facilities would result in higher bicycling levels in the overall population (i.e., a causal relationship), or whether this relationship is an artifact of mere statistical association between neighborhoods' bicycling-facilities and the bicycling levels of individuals in those neighborhoods. Such non-causal association may occur because individuals of certain sociodemographic characteristics, attitudes and lifestyle preferences (say, those who are physical fitness conscious and bicycling-inclined, and those who own bicycles) self-select themselves to reside in neighborhoods with good bicycling facilities that allow them to participate in bicycling activities. It is also possible that individuals of certain characteristics may self-select into neighborhoods with high bicycling facilities because of other reasons that are not directly activity-related. In any event, if such residential self-selection process is at work, building neighborhoods with good bicycling facilities would not result in higher bicycling levels in the overall population, but simply lead to an alteration of spatial residence patterns of the population based on the factors due to which individuals self-select into residential locations. ${ }^{2}$

In reality, the nature of the relationship between land-use and travel behavior may be part causal and part associative. Thus, any attempt to examine the land use-travel behavior connection should disentangle the causal and associative elements of the relationship to inform and contribute to the credible assessment of the impact of land-use policies on travel behavior. To be sure, several recent studies have alluded to and/or accommodated residential self-selection in one of several ways. However, all these earlier studies study the land use and travel behavior relationship by directly focusing on specific travel behavior dimensions, such as trip frequency or trip mileage for one or more trip purposes. ${ }^{3}$ Essentially, these earlier studies adopt a trip-based

\footnotetext{
${ }^{2}$ As indicated in Bhat and Guo (2007), the assumption here is that there is an adequate supply of neighborhoods to choose from for individuals who are bicycling-oriented. If there is an undersupply of such neighborhoods, then enhancing bicycling facilities in some neighborhoods would increase overall bicycling activity across the population even if the only process at work is residential self-selection.

${ }^{3}$ See Cao et al. (2005, 2006b), Chatman (2005), Kitamura et al. (1997), Schwanen and Mokhtarian (2003), Boarnet and Sarmiento (1998), Greenwald and Boarnet (2001), Khattak and Rodriguez (2005), Handy et al. (2005), Handy and Clifton (2001), and Krizek (2000 and 2003) for analyses of residential self selection in models of trip frequency by one or more modes and/or purposes; Schwanen and Mokhtarian (2005a), Khattak and Rodriguez (2005), Bagley and Mokhtarian (2002), Handy et al. (2005), and Krizek (2000, 2003) for analyses of residential self selection in models of travel mileage by one or more modes; Cervero and Duncan (2002), Hammond (2005), Pinjari et al. (2007), Schwanen and Mokhtarian (2005b), Salon (2006), and Zhang (2006) for commute mode choice analyses that consider residential self selection; and Cervero and Duncan (2003), Greenwald (2003), and Salon (2006) for noncommute mode choice analyses that accommodate residential self selection. The reader is also referred to Bhat and
} 
approach to analyze the interactions between land use and travel demand, ignoring the conceptual and behavioral limitations of the trip-based approach (see Jones et al., 1990, Axhausen and Garling, 1992, Kurani and Kitamura, 1996, Bhat and Koppelman, 1999, Bhat et al., 2004, and Vovsha and Bradley, 2005 for detailed discussions of the shortcomings of the tripbased method; space constraints do not allow us to discuss these limitations in this paper).

\subsection{Activity-based Travel Demand Modeling}

The activity-based approach to travel demand analysis overcomes the conceptual and behavioral inadequacy of the trip-based approach by (1) recognizing that travel is derived from a more fundamental need to perform activities distributed in time and space, (2) focusing on entire sequences and patterns of activities and travel over the course of a day rather than individual trips, (3) recognizing the linkages among activity-travel decisions of an individual across different time periods of the day, (4) explicitly modeling the temporal dimension of activity participations and travel, and (5) accommodating space-time interactions in activities and travel. All of these aspects of the activity-based approach may be traced back to a single fundamental difference between the trip-based approach and the activity-based approach, which is in the way time is conceptualized and represented in the two approaches (see Pas, 1996, Pas and Harvey, 1997, and Bhat and Koppelman, 1999). In the trip-based approach, time is reduced to being simply a "cost" of making a trip. The activity-based approach, on the other hand, treats time as an all-encompassing continuous entity within which individuals make activity/travel participation decisions (see Kurani and Lee-Gosselin, 1996). Thus, the central basis of the activity-based approach is that individuals' activity-travel patterns are a result of their time-use decisions. Individuals have 24 hours in a day (or multiples of 24 hours for longer periods of time) and decide how to use that time among activities and travel (and with whom) subject to their sociodemographic, spatial, temporal, transportation system, and other contextual constraints. In the activity-based approach, the impact of land-use and demand management policies on time-use behavior is an important precursor step to assessing the impact of such polices on individual travel behavior. For example, one may analyze whether improving a neighborhood with walkways, bikeways, and recreational parks encourages individuals to invest more time in physically active recreation pursuits in the place of in-home passive recreation (such as watching television or playing computer games). The travel dimensions then can be "derived" from the changes in time-use and activity-scheduling patterns.

To be sure, there have been several studies of individual time-use in the past decade. However, most of these studies have focused on understanding time-use patterns as a function of individual and household sociodemographics (see, for example, Bhat and Misra, 1999, Chen and Mokhtarian, 2006, Gliebe and Koppelman, 2002, Golob and McNally, 1995, Goulias and Henson, 2006, Harvey and Taylor, 2000, Kapur and Bhat, 2007, Kitamura et al., 1997, Kraan, 1996, Levinson, 1999, Lu and Pas, 1997 and 1999, Meloni et al., 2004, Meloni et al., 2007, Yamamoto and Kitamura, 1999, and Ye and Pendyala, 2005). Such time-use studies, while contributing to the literature in important ways, are unable to examine the impact of land-use policies. Some more recent studies by Bhat and colleagues do include the impact of a comprehensive set of land use attributes in their time-use analyses (see, for example, Bhat, 2005, Bhat et al., 2006, Copperman and Bhat, 2007, and Sener and Bhat, 2007). However, these studies are focused on weekend day time-use behavior and not weekday time-use behavior.

Guo (2007) and Cao et al., (2006a) for an overview of studies that address residential self-selection in examining land use variable impacts on travel dimensions. 
Besides, an important limitation of all these earlier activity-based time-use studies is that they do not consider residential self-selection effects when assessing the impact of land use attributes. Rather, they assume land use as being pre-determined and exogenous.

\subsection{The Current Research}

The discussion in the previous sections indicates the substantial earlier research on integrated land use-travel demand modeling and activity-based travel demand modeling. While the research on integrated land use-travel demand modeling has been driven by a need to assess land use policies, the emergence of the activity-based approach may be attributed to the need to understand individual-level behavioral responses to demand management policies. These two streams of research have progressed in rather independent directions. In particular, integrated land use-travel demand models have adopted a trip-based approach, while activity-based travel demand models have adopted a “dis-integrated” land use-travel demand approach.

In the current research, we bring the foregoing two streams of research together in the context of a joint model of traffic analysis zone (TAZ)-level residential choice and individual activity time-use behavior. Specifically, we accommodate residential self-selection effects due to observed and unobserved individual characteristics in examining the impact of activity-travel environment (ATE) variables on individual time-use in maintenance activity (grocery shopping, household chores, personal care, etc.) and several types of discretionary activity purposes. ${ }^{4}$ The residential choice-activity time use model system in the paper takes the form of a joint mixed multinomial logit - multiple discrete-continuous extreme value (MNL-MDCEV) model. To our knowledge, this is the first instance in the econometric or other literature of the development of such a model to jointly analyze an unordered discrete variable (residential location choice in the current context) and multiple discrete-continuous variables (activity participations and time-use decisions in multiple activities in the current context).

The remainder of this paper is organized as follows. Section 2 presents the mathematical structure of the joint model and the estimation procedure. Section 3 discusses the data sources, the ATE measures constructed, and the sample used in the analysis. Section 4 focuses on the empirical results. Section 5 demonstrates an application of the model to predict activity time-use changes in response to changes in specific ATE policies. Finally, Section 6 concludes the paper by summarizing important findings and identifying directions for future research.

\section{ECONOMETRIC MODELING FRAMEWORK}

\subsection{Model Structure}

Let $q(q=1,2, \ldots, Q)$ be an index for the decision-maker, $k(k=1,2, \ldots, K)$ be the index for activity purpose, and $i(i=1,2, \ldots, I)$ be the index for the spatial unit of residence. Let $T_{q}$ be the total amount of time available to individual $q$ for participation in maintenance and

\footnotetext{
${ }^{4}$ In the rest of this paper, we will use the more general term ATE instead of land-use. The ATE attributes of a traffic analysis zone (TAZ) include the sociodemographic, natural, and built environment characteristics of the TAZ, as well as the transportation system facility characteristics in and around the TAZ. The sociodemographic environment may include such characteristics as the ethnic composition, age distribution, and income level distribution in the TAZ; the natural environment comprises vegetation, gardens, parks, and water bodies; the built environment consists of the urban form design, land-use structure (such as land-use mix, employment and residential density), and spatial distribution of the activity centers; and the transportation system consists of the elements of transportation infrastructure, such as highways, bikeways, transit systems, local streets, and side walks etc., and the accessibility and level-of-service offered by the transportation infrastructure for various activities and travel.
} 
discretionary activity purposes, and let $\boldsymbol{t}_{q}=\left\{t_{q 1}, t_{q 2}, \ldots, t_{q k}\right\}$ be the vector of time investments in maintenance activity $\left(t_{q 1}\right)$ and discretionary activities $\left(t_{q 2}, t_{q 3}, \ldots, t_{q k}\right)$. All individuals in the sample participate for some non-zero amount of time in maintenance activity, and hence this alternative constitutes the "outside good" in the MDCEV component of the model system (see Bhat, 2008). ${ }^{5}$

Using the above notational preliminaries, we next discuss the structure of the residential location choice model component (Section 2.1.1), the time use model component (Section 2.1.2), and then highlight the joint nature of the two components (Section 2.1.3).

\subsubsection{The Residential Location Component}

The residential location component takes the familiar discrete choice formulation, as presented below:

$u_{q i}^{*}=\varphi_{q}^{\prime} z_{q i}+\xi_{q i}$, spatial unit $i$ chosen if $u_{q i}^{*}>\max _{\substack{d, 1,2, \ldots, I \\ d \neq i}} u_{q l}^{*}$.

In the equation above, $u_{q i}^{*}$ is the indirect (latent) utility that the $q^{\text {th }}$ individual (as part of her/his household) obtains from locating in spatial unit $i, z_{q i}$ is a vector of ATE attributes corresponding to individual $q$ and spatial unit $i$ (such as land-use mix and measures of activity accessibility), and $\varphi_{q}$ is a coefficient vector capturing individual $q$ 's sensitivity to attributes in $z_{q i}$. We parameterize each element $l$ of $\varphi_{q}$ as $\varphi_{q l}=\left(\varphi_{l}+\lambda_{l}^{\prime} w_{q l}+v_{q l}+\sum_{k} \omega_{q k l}\right)$, where $w_{q l}$ is a vector of observed individual-specific factors (such as income and/or household size of individual $q$ 's household) affecting sensitivity to the $l^{\text {th }}$ attribute in vector $z_{q i}$, and $v_{q l}$ and $\left(\sum_{k} \omega_{q k l}\right)$ are individual-specific unobserved factors impacting individual $q$ 's and her/his household's sensitivity to the $l^{\text {th }}$ attribute in vector $z_{q i}$. $v_{q l}$ includes only those individual-specific unobserved factors that influence sensitivity to residential choice, while each $\omega_{q k l}(k=2,3, \ldots, K)$ includes only those individual-specific unobserved factors that influence both residential choice and time use in discretionary activity purpose $k$. For instance, consider an individual's sensitivity to bicycling facilities around her/his household. The individual may have a higher sensitivity (than her or his observationally equivalent peer group) to bicycling facility density because of general auto disinclination. This auto disinclination may not, however, impact time use in activities. This would be captured in $v_{q l}$. Now, another unobserved individual factor may be fitness consciousness. This is likely to impact the sensitivity to bicycling facility density in residential choice (because better bicycling facilities are more conducive to bicycling activity) and also influence time invested in physically active leisure. This would be included in $\omega_{q k l}$ (more on this later). Finally, in Equation (1), $\xi_{q i}$ is an idiosyncratic error term assumed to be identically and independently extreme-value distributed across spatial alternatives and individuals.

\footnotetext{
${ }^{5}$ The term "outside good" refers to a good that is "outside" the purview of the choice of whether to be consumed or not. That is, the "outside good" is a good that is always consumed by all consumers.
} 


\subsubsection{The Time Use Model Component}

Designate the first alternative as maintenance activity, which is also the outside good that is always consumed. The rest of the $(K-1)$ alternatives correspond to discretionary activities. Consider the following additive utility function form ${ }^{6}$ :

$$
U_{q i}\left(\boldsymbol{t}_{q}\right)=\frac{1}{\alpha_{1}} \psi_{q 1 i} t_{q 1}^{\alpha_{1}}+\sum_{k=2}^{K} \gamma_{k} \psi_{q k i} \ln \left(\frac{t_{q k}}{\gamma_{k}}+1\right)
$$

In the above utility function, $\boldsymbol{t}_{q}$ is the vector of time investments $\left(t_{q 1}, t_{q 2}, \ldots, t_{q k}\right)$ of individual $q$, or equivalently, the time spent in each activity purpose. ${ }^{7} U_{q i}\left(\boldsymbol{t}_{q}\right)$ refers to the utility accrued to the individual due to time investment $\boldsymbol{t}_{q}$ if s/he resides in spatial unit $i$. The term $\psi_{q k i}$ corresponds to the marginal random utility of one unit of time investment in alternative $k$ at the point of zero time investment for the alternative for the individual residing in spatial unit $i$ (as can be observed by computing $\left.\partial U_{q i}\left(\boldsymbol{t}_{q}\right) /\left.\partial t_{q k}\right|_{t_{q k}=0}\right)$. Thus $\psi_{q k i}$ controls the discrete choice participation decision in alternative $k$ for individual $q$ residing in spatial unit $i$. We will refer to this term as the baseline preference for alternative $k$. The term $\gamma_{k}$ is a translation parameter that serves to allow corner solutions (zero consumption) for the "inside" alternatives $k=2,3, \ldots, K$ $\left(\gamma_{k}>0\right)$. However, it also serves to accommodate satiation effects due to diminishing marginal utility with increasing time investment in these inside alternatives. Specifically, values of $\gamma_{k}$ closer to zero imply higher satiation (or lower time investment) for a given level of baseline preference (see Bhat, 2008). There is no $\gamma_{1}$ term for the first alternative in Equation 2 because it is always consumed. However, satiation effects in the consumption of this first alternative are captured through the exponential $\alpha_{1}$ parameter, which is bounded from above by a value of 1 (so that marginal utility decreases with increasing time investment in maintenance activity). The

\footnotetext{
${ }^{6}$ The utility function used here is a special case of a generalized variant of the translated constant elasticity of substitution (CES) direct utility function proposed by Bhat (2008). The basic form of Bhat's utility function is suitable to model individual activity time-use behavior in several ways. First, the function assumes that utility is gained from investing time in discretionary activities. This is a reasonable assumption since individuals have the choice not to participate in such activities. Also the reader will note that the inclusion of the maintenance activity type (the first alternative) allows the analyst to endogenously estimate the total amount of time invested in discretionary pursuits. Second, as explained in the subsequent discussion, the functional form allows for the possibility that individuals may not participate in certain types of activities (i.e., corner solutions of zero time investment in certain types of activities). Third, the nonlinear functional form accommodates satiation effects in time investment due to diminishing marginal utility with increasing time investment in a particular type of activity. Such satiation effects lead to participation in multiple types of activities as opposed to a single activity. Fourth, the utility function with type-I extreme value distributed stochastic terms yields simple closed form probability expressions for any time-use pattern. In this analysis, several specific forms of the general utility function proposed by Bhat (2008) were considered. Among all the functional forms, the one below provided the best data fit. The reader is referred to Bhat (2008) for a detailed discussion of the utility form and additional details on the properties of the utility function.

${ }^{7}$ The individual has the vector $\boldsymbol{t}_{q}$ as the decision vector. The second through $K^{\text {th }}$ elements of $\boldsymbol{t}_{q}$ can either be zero or some positive value (the first element of $\boldsymbol{t}_{q}$ should be positive). Whether or not a specific $t_{q k}$ value $(k=2,3, \ldots, K)$ is zero constitutes the discrete choice component, while the magnitude of each non-zero $t_{q k}$ value constitutes the continuous choice component. In the rest of this paper, we will use the terms "time investments" and "time use" interchangeably to refer to these discrete-continuous $t_{q k}$ values.
} 
constraints that $\alpha_{1} \leq 1$ and $\gamma_{k}>0(k=2,3, \ldots, K)$ are maintained through appropriate parameterizations (see Bhat, 2008 for details). ${ }^{8}$

To complete the model specification, we express the baseline parameters as functions of observed and unobserved attributes corresponding to the individual $q$ and spatial unit $i$ as follows: $\psi_{q k i}=\exp \left(\beta_{q k}^{\prime} z_{q i}+\theta_{k}^{\prime} x_{q}+\varepsilon_{q k i}\right)$, where $z_{q i}$ is an ATE vector of observed attributes with individual-specific parameter vector $\beta_{q k}$, and $x_{q}$ is a vector of pure individual sociodemographics with coefficient vector $\theta_{k} \cdot{ }^{9}$ We further parameterize $\beta_{q k}$ as follows: $\beta_{q k l}=\beta_{k l}+\Delta_{k l} s_{q l}+\eta_{q k l}$, where $s_{q l}$ is a vector of observed individual-specific factors influencing the sensitivity of individual $q$ to the $l^{\text {th }}$ ATE attribute in vector $z_{q i}$ through the $\Delta_{k l}$ coefficient, and $\eta_{q k l}$ is a term capturing the impact of individual-specific and purpose-specific unobserved terms on the sensitivity to the $l^{\text {th }}$ ATE attribute in $z_{q i}$. $\eta_{q k l}$ is next partitioned into two components: $\sum_{l}\left( \pm \omega_{q k l}\right) z_{q i l}+\zeta_{q k i}$. The $\left( \pm \omega_{q k l}\right) z_{q i l}$ terms are the common error components in the residential location and time investment model components, while $\zeta_{q k i}$ is an idiosyncratic term assumed to be identically and independently standard type I extreme-value distributed across individuals, activity purposes, and spatial units. ${ }^{10}$

\subsubsection{The Joint Model System}

The specifications in the previous two sections may be collected and brought together in the following equation system:

$$
\begin{aligned}
u_{q i}^{*}=\sum_{l} & \left(\varphi_{l}+\lambda_{l}^{\prime} w_{q l}+v_{q l}\right) z_{q i l}+\sum_{k}\left(\sum_{l} \omega_{q k l}\right) z_{q i l}+\xi_{q i} \\
U_{q i}\left(\boldsymbol{t}_{q}\right)= & \frac{1}{\alpha_{1}} \exp \left(\zeta_{q 1 i}\right) t_{q 1}^{\alpha_{1}}+ \\
& \sum_{k=2}^{k}\left\{\gamma_{k} \exp \left[\left\{\sum_{l}\left(\beta_{k l}+\Delta_{k l} s_{q l}+\eta_{q k l}\right) z_{q i l}\right\}+\theta_{k}^{\prime} x_{q}+\left\{\sum_{l}\left( \pm \omega_{q k l}\right) z_{q i l}\right\}+\zeta_{q k i}\right] \ln \left[\frac{t_{q k}}{\gamma_{k}}+1\right]\right\}
\end{aligned}
$$

\footnotetext{
${ }^{8}$ The $\alpha$ and $\gamma$ parameters are subscripted only by activity purpose $k$ (unlike the $\psi$ parameters) because specification tests in our empirical analysis did not show statistically significant variation in these parameters based on individual and spatial unit-related characteristics.

${ }^{9}$ Note that we are introducing the full vector $z_{q i}$ of ATE attributes in both the residential choice and time investment model components. In general, some ATE attributes will not impact residential choice (the corresponding element of $\varphi_{q}$ is zero for all $q$ ) and some will not influence time investments in activity type $\mathrm{k}$ (the corresponding element of $\beta_{q k}$ is zero for all q). Additionally, it is possible that ATE attributes have a mean effect of zero across individuals for residential choice and/or one or more activity purpose time investments, but have a significant distribution around the zero mean.

${ }^{10}$ In our empirical analysis, we further partitioned $\zeta_{q k i}$ into error components that generate covariance (and hence higher sensitivity and substitution effects) across discretionary activity purposes (for example, individuals who are generically inclined toward social activities may have a higher baseline preference than their observationally equivalent peers for both in-home and out-of-home social activities). However, in our final specification, we did not find any such statistically significant covariance terms. Thus, for simplicity in presentation, we are imposing the restriction of zero covariances across discretionary activity purposes in the model structure presentation.
} 
In the above equation system, the vectors $z_{q i}$ and $x_{q}$ do not appear for the first alternative in $U_{q i}\left(\boldsymbol{t}_{q}\right)$ because only utility differences matter. From the analyst's perspective, individuals are choosing a residential location $i$ and their time use profile by jointly maximizing $u_{q i}^{*}$ and $U_{q i}\left(\boldsymbol{t}_{q}\right)$ subject to the budget constraint that $\sum_{k} t_{q k}=T_{q}$, where $T_{q}$, as mentioned earlier, is the total time available to individual $q$ for participation in maintenance and discretionary activities.

The joint nature of the model system arises because of the presence of the common unobserved $\omega_{q k l} z_{q i l}$ terms in the residential choice and time investment model components. More generally, the model system allows self-selection of individuals (based on their time-use preferences and other factors) into neighborhoods due to both observed and unobserved factors. In the context of observed factors, consider the situation where individuals who own bicycles are attracted toward residential neighborhoods with very good bicycling facilities. This can be reflected by including bicycle ownership as a variable in the $w_{q l}$ vector that corresponds to the "bicycling facility density" variable in the $z_{q i}$ vector of the residential choice equation. Individuals who own bicycles may also be more likely to spend time in physically active recreational pursuits, which can be accommodated by including bicycle ownership as a variable in the $x_{q}$ vector in the time investment model component. If bicycle ownership were not included in the $x_{q}$ vector for the physically active recreation purpose in the time investment equation, and if "bicycling facility density" were included as a variable in the $z_{q i}$ vector of the same equation, the result could be an inflated estimate of the positive influence of bicycling facility density on time invested in physically active recreation. Similarly, consider an unobserved individual factor, such as fitness consciousness, that makes some individuals locate in areas with good bicycling facility and also participate more than their observationally equivalent peers in physically active recreation. Such factors are captured in the common $\omega_{q k l} z_{q i l}$ terms in the two equations. The ' \pm ' sign in front of the $\omega_{q k l} z_{\text {qil }}$ terms in the time-investment model component indicates that the correlation in the unobserved factor $l$ may be positive or negative. If the sign is positive (negative), it implies that individuals who intrinsically prefer the ATE characteristics represented by $z_{q i l}$ also have a higher (lower) generic preference for activity purpose $k$.

As indicated earlier, from the analyst's perspective, individuals are choosing a residential location $i$ and their time use (or allocation) profile $\boldsymbol{t}_{q}$ by jointly maximizing $u_{q i}^{*}$ and $U_{q i}\left(\boldsymbol{t}_{q}\right)$ subject to the budget constraint that $\sum_{k} t_{q k}=T_{q}$. That is, for the residential location choice component, a traditional random utility maximization based discrete choice framework is adopted in that spatial unit $i$ is chosen for residential location if $u_{q i}^{*}>\max _{\substack{d=1,2, \ldots, I \\ d \neq i}} u_{q l}^{*}$. This results in a familiar multinomial logit type choice probability for the residential location choice component, given by: 


$$
P_{q}(i)=\frac{\exp \left[\sum_{l}\left(\varphi_{l}+\lambda_{l}^{\prime} w_{q l}+v_{q l}+\sum_{k} \omega_{q k l}\right) z_{q i l}\right]}{\sum_{j} \exp \left[\sum_{l}\left(\varphi_{l}+\lambda_{l}^{\prime} w_{q l}+v_{q l}+\sum_{k} \omega_{q k l}\right) z_{q i l}\right]}
$$

For the time-use choice component, the optimal time use profile $\boldsymbol{t}_{q}^{*}=\left\{t_{q 1}^{*}, t_{q 2}^{*}, \ldots, t_{q K}^{*}\right\}$ can be found by forming the Lagrangian and applying the Kuhn-Tucker (KT) conditions. The Lagrangian function for the problem is:

$$
\begin{aligned}
\mathscr{L} & =\frac{1}{\alpha_{1}} \exp \left(\zeta_{q 1 i}\right) t_{q 1}^{\alpha_{1}} \\
& +\sum_{k=2}^{k}\left\{\gamma_{k} \exp \left[\left\{\sum_{l}\left(\beta_{k l}+\Delta_{k l} s_{q l}+\eta_{q k l}\right) z_{q i l}\right\}+\theta_{k}^{\prime} x_{q}+\left\{\sum_{l}\left( \pm \omega_{q k l}\right) z_{q i l}\right\}+\zeta_{q k i}\right] \ln \left[\frac{t_{q k}}{\gamma_{k}}+1\right]\right\} \\
& -\lambda\left[\sum_{k} t_{q k}-T_{q}\right]
\end{aligned}
$$

The stochastic KT first order conditions for the above Lagrangian function can be written as (Bhat, 2008):

$V_{q k i}+\zeta_{q k i}=V_{q 1 i}+\zeta_{q 1 i}$ if $t_{q k}^{*}>0,(k=2,3, \ldots, K)$

$V_{q k i}+\zeta_{q k i}<V_{q 1 i}+\zeta_{q 1 i}$ if $t_{q k}^{*}=0,(k=2,3, \ldots, K)$, where

$V_{q 1 i}=\left(\alpha_{1}-1\right) \ln t_{q 1}^{*}$, and

$V_{q k i}=\left[\left\{\sum_{l}\left(\beta_{k l}+\Delta_{k l} S_{q l}+\eta_{q k l}\right) z_{q i l}\right\}+\theta_{k}^{\prime} x_{q}+\left\{\sum_{l}\left( \pm \omega_{q k l}\right) z_{q i l}\right\}\right]-\ln \left(\frac{t_{q k}^{*}}{\gamma_{k}}+1\right)$ for $k=2,3, \ldots, K$

Using the stochastic KT conditions above (and the IID type 1 extreme value distribution of the $\zeta_{q k i}$ terms), the probability of optimal (or observed) time allocations $t_{q}^{*}=\left\{t_{q 1}^{*}, t_{q 2}^{*}, \ldots, t_{q K}^{*}\right\}$ can be written as (Bhat, 2008):

$P_{q i}\left(\boldsymbol{t}_{q}^{*}\right)=\left|J_{q}\right| \frac{\prod_{h=1}^{M_{q}} e^{V_{q h i}}}{\left(\sum_{k=1}^{K} e^{V_{q k i}}\right)^{M_{q}}}\left(M_{q}-1\right) !$ 
where $M_{q}$ is the number of activity purposes in which the individual $q$ participates, and

$$
\left|J_{q}\right|=\left(\prod_{h=1}^{M_{q}} c_{q h}\right)\left(\sum_{h=1}^{M_{q}} \frac{1}{c_{q h}}\right), c_{q 1}=\frac{1-\alpha_{1}}{t_{q 1}^{*}}, c_{q h}=\frac{1}{t_{q 1}^{*}+\gamma_{h}},\left(h=2, \ldots, M_{q}\right) .
$$

Given the probability of the residential spatial unit choice component (in Equation 4) and that of the time-use choice component (in Equation 7), the joint residential location and time use choice probability can be obtained by multiplying the probabilities of the two choice components.

\subsection{Model Estimation}

The parameters to be estimated in the equation system (3) include the $\varphi_{l}, \lambda_{l}, \Delta_{k l}$, and $\theta_{k}$ vectors, the $\gamma_{k}(k=2,3, \ldots, K), \alpha_{1}$, and $\beta_{k l}$ scalars $(k=2,3, \ldots, K ; l=1,2, \ldots, L)$, and the variances of the stochastic components $v_{q l}, \eta_{q k l}$, and $\omega_{q k l}$ (all assumed to be normally distributed with variances $\sigma_{v l}^{2}, \sigma_{\eta k l}^{2}, \sigma_{\omega k l}^{2}$, respectively) that represent random heterogeneity.

Let $\Omega$ represent a vector that includes all the parameters to be estimated, and let $\Omega_{-\sigma}$ represent a vector of all parameters except the variance terms. Also, let $g_{q}$ be a vector that stacks the $v_{q l}, \eta_{q k l}$, and $\omega_{q k l}$ terms, and let $\Sigma$ be a corresponding vector of standard errors. Define $a_{q i}=1$ if individual $q$ resides in spatial unit $i$ and 0 otherwise. Then the likelihood function for a given value of $\Omega_{-\sigma}$ and $g_{q}$ may be written for an individual $q$ as:

$$
\begin{aligned}
L_{q}\left(\Omega_{-\sigma}\right) \mid g_{q}=\prod_{i=1}^{I}\{ & \left\{\frac{\exp \left[\sum_{l}\left(\varphi_{l}+\lambda_{l}^{\prime} w_{q l}+v_{q l}+\sum_{k} \omega_{q k l}\right) z_{q i l}\right]}{\sum_{j} \exp \left[\sum_{l}\left(\varphi_{l}+\lambda_{l}^{\prime} w_{q l}+v_{q l}+\sum_{k} \omega_{q k l}\right) z_{q i l}\right]}\right] \times \\
& {\left.\left[\left|J_{q}\right| \frac{\prod_{h=1}^{M_{q}} e^{V_{q h i}}}{\left(\sum_{k=1}^{K} e^{V_{q k i}}\right)^{M_{q}}}\left(M_{q}-1\right) !\right]\right\} }
\end{aligned}
$$

Subsequently, the unconditional likelihood function can be computed for individual $q$ as:

$$
L_{q}(\Omega)=\int_{g_{q}}\left(L_{q}\left(\Omega_{-\sigma}\right) \mid g_{q}\right) d \boldsymbol{F}\left(g_{q} \mid \Sigma\right)
$$

where $\boldsymbol{F}$ is the multidimensional cumulative normal distribution. The log-likelihood function can be written as: $L(\Omega)=\sum_{q} \ln L_{q}(\Omega)$. Simulation techniques are applied to approximate the 
multidimensional integral in Equation (8), and the resulting simulated log-likelihood function is maximized. Specifically, the scrambled Halton sequence (see Bhat, 2003) is used to draw realizations from the population normal distribution. In the current paper, we tested the sensitivity of parameter estimates with different numbers of scrambled Halton draws per observation, and found the results to be stable with as few as 100 draws. In the analysis, we used 125 draws per observation in the estimation.

\section{THE DATA}

\subsection{Data Sources}

The primary source of data used for this analysis is the 2000 San Francisco Bay Area Travel Survey (BATS) designed and administered by MORPACE International Inc. for the Bay Area Metropolitan Transportation Commission (MTC). The survey collected information on all activity episodes (in-home and out-of-home) undertaken by individuals from over 15,000 households in the Bay Area for a two-day period (see MORPACE International Inc., 2002, for details on survey, sampling and administration procedures). Information characterizing the context (activity type, start and end times of the activity, and location of participation) of each activity episode was collected. Furthermore, data on individual and household sociodemographics was also obtained.

In addition to the 2000 BATS data, several other secondary data sources were used to derive spatial variables characterizing the activity-travel environment in the region. These include: (1) Land-use/demographic coverage data, obtained from the MTC, (2) The zone-to-zone motorized travel level of service files, obtained from MTC, (3) The Census 2000 population and Housing data summary files (SF1), (4) GIS layers of businesses (automotive businesses, shopping and grocery stores, medical facilities and personal services, food stores, sports and fitness centers, parks and gardens, restaurants, recreational businesses, and schools), obtained from the InfoUSA business directory, (5) GIS layers of bicycling facilities, also obtained from MTC, and (6) GIS layers of highway (interstate, national, state and county highways) network and local roadways (local, neighborhood, and rural roads) network, extracted from the Census 2000 Tiger files.

\subsection{Sample Formation}

\subsubsection{Sample Extraction}

Several steps were undertaken to generate the data for the current analysis. First, only adults (individuals 16 years or older) were selected to focus the analysis on the demographic segment that clearly exercises a choice in activity participation and time allocation. Second, only weekday data was selected from the sample, since the focus of our analysis is on the time-use patterns on weekdays. Third, of the two-day activity diary data available for each individual, only one randomly chosen day was picked. In addition, we restricted the analysis to the time-use patterns of a single randomly chosen individual from each household. These decisions were made to keep the sample size manageable in the estimations, and also to avoid the problem of repeated data measurement from the same individual and/or household. Fourth, we selected only the non-work episodes for each individual. Finally, we confined the analysis to Alameda County in the San Francisco Bay area. 


\subsubsection{Activity Type Classification}

The survey instrument used a 17-category activity purpose classification scheme, and collected information on the location of each activity episode. The activity purpose and location information was used to create a 13-category activity purpose typology in the current study to classify non-work episodes. The activity purposes are: (1) Maintenance (household chores, personal care, meal preparation, grocery shopping, and medical appointments), (2) In-home (IH) internet browsing, (3) Out-of-home $(\mathrm{OH})$ volunteering (including religious and civic activity participation), (4) $\mathrm{OH}$ non-maintenance shopping (i.e., shopping for non-grocery purposes), (5) IH socializing, (6) $\mathrm{OH}$ socializing, (7) IH relaxing (resting, reading, listening to music, etc.), (8) IH recreation (hobbies, television viewing, etc.), (9) $\mathrm{OH}$ meals, (10) $\mathrm{OH}$ physically active pure recreation (episodes undertaken using non-motorized modes, and without any specific destination, such as walking, jogging, or bicycling around the neighborhood, are classified in this category), (11) $\mathrm{OH}$ physically inactive pure recreation (episodes undertaken using motorized modes, and without any specific destination, such as joy-riding around the block, belong to this category), (12) $\mathrm{OH}$ physically active recreation (exercising at the gym, playing tennis, etc.), and (13) $\mathrm{OH}$ physically passive recreation (going to the movies, opera show, etc.). The dependent variables in the time investment component of the model system correspond to the time allocated during the 24-hour survey weekday to each of the 13 activity purposes just identified. These variables are obtained by appropriate time aggregation across all episodes within each purpose category for each individual. The total time across all these 13 categories is considered exogenous, and the model focuses on residential choice and daily time-use in each of the 13 activity purpose categories.

\subsubsection{Activity Travel Environment (ATE) Measures}

The data from the secondary sources identified in Section 3.1 were used to compute a host of built environment measures for each traffic analysis zone (TAZ), including:

1. Zonal size and density measures, such as total population, population density, household density, density of employment by each of several employment categories, and dummy variables for central business district (CBD), urban, suburban, and rural areas (computed based on employment density). These attributes were obtained from the zonal land-use data file.

2. Zonal land-use structure variables, such as housing type measures (fractions of single family, and multiple family dwelling units), fractions of zonal area in residential and commercial land-uses, and land-use mix (see Bhat and Gossen, 2004 for a description of the land-use mix variable; the variable takes a value of zero for zones with only one type of land-use and a value of 1 for zones with equal distributions in area among residential, commercial, and other land-uses). The zonal land-use structure variables were constructed from the zonal land-use data file.

3. Regional accessibility measures, such as shopping accessibility, recreational accessibility, and employment accessibility. These are Hansen-type (see Fotheringham, 1983) accessibility measures computed from the zonal land-use and level-of-service data.

4. Zonal demographics, such as average household size, median household income, and average housing cost. These demographic measures were derived from the Census 2000 population and housing data summary file (SF1). 
5. Zonal ethnic composition measures, constructed as fractions of Caucasian, AfricanAmerican, Hispanic, Asian, and other ethnicity populations, also derived from the Census 2000 population and housing data summary file.

6. Zonal activity opportunity variables, such as activity center intensity (i.e., the number of business establishments per square mile) and density (i.e., the number of business establishments per square mile) for each of the following activity types (extracted from the InfoUSA business establishments data): (a) maintenance (grocery stores, gas stations, food stores, car wash, automotive businesses, banks, medical facilities, etc.), (b) physically active recreation (fitness centers, sports centers, dance and yoga studios, parks, gardens, etc.), (c) Physically inactive recreation (theatres, amusement centers, arcades, etc.), and (d) eat-out (restaurants and eateries).

7. Zonal transportation network measures, such as highway density (miles of highway facilities per square mile), bikeway density (miles of bikeway facilities per square mile), and local roadway density (miles of roadway density per square mile). These variables were extracted from the GIS layers of bikeways and roadways. In the context of transportation network supply side measures, it is desirable to explore several more variables, specifically those relating to the structure of network that can potentially influence residential and activitytravel choices (see, for example, Snellen et al., 2002 and Levinson and Yerra, 2006 for extensive discussions on transportation network structure).

All of these ATE attributes were merged with the activity time-use and individual/household demographic data to form a comprehensive database suitable for modeling residential choice and time-investment decisions.

\subsection{Sample Description}

The final estimation sample consists of 2793 individuals residing in Alameda County in the San Francisco Bay area. Each individual has the choice of residing in any one of 236 zones in Alameda County, which is modeled using a standard discrete choice formulation. In this residential choice model, we do not undertake a sampling scheme to reduce the number of alternatives because our overall residential choice model does not correspond to a simple multinomial logit model (rather there is mixing in the model).

The time-use of individuals in each of 13 activity purposes constitutes the dependent variables of the MDCEV component of the model system. Each (and all) of the 2793 individuals participated in maintenance activity. The frequency distribution of individuals based on the number of discretionary activity types they participated in is provided in Table 1. As can be observed, 32.6\% of individuals did not participate in any discretionary activity, while the remaining $67.4 \%$ of individuals participated in at least one type of discretionary activity. Of the individuals who participated in at least one type of discretionary activity, $51.2 \%$ of individuals participated in multiple types of discretionary activities. Overall, the results clearly illustrate the high prevalence of participating in multiple non-work activity purposes on a single weekday, providing strong support for the use of the MDCEV model for time-use analysis.

\section{EMPIRICAL ANALYSIS}

\subsection{Variable Specification}

Several types of variables were considered in the joint modeling system. These included: (1) household socio-demographics (household size, household composition and family structure, vehicle and bicycle ownership, ethnicity, income, whether or not household owned or rented its 
residence, dwelling type, availability of internet, etc.), (2) individual demographics and employment characteristics (age, license holding to drive, employment status, number of hours of work on the day, physical disability status etc.), (3) contextual variables such as season of the year, day of the week, rain-fall (and the amount of rain fell) in the day, temperature (minimum and maximum values in the day, and the variation in the day), (4) a host of activity-travel environment variables (discussed in Section 3.2.3) and commute-related variables, and (5) the interactions of the activity-travel environment variables and commute variables with household and individual socio-demographics.

The final variable specification was obtained based on a systematic process of eliminating variables found to be statistically insignificant at the 0.05 level of significance, and parsimony in representation. The specification was additionally guided by intuitive considerations, and results from earlier studies. Also, in our specification analysis, we retained some ATE-related variables whose coefficients had a t-statistic value of 1.00 or higher (even if the t-statistic is lower than 1.96) because the ATE variables in this study are computed at the rather coarse level of traffic analysis zones. But these effects were intuitive, and our intent in including these was that they could aid future research work that considers ATE measures at a finer spatial resolution by identifying potential ATE variables of importance in residential location and activity time use decisions.

In the next section (Section 4.2), we discuss the results of the residential location choice model component. Section 4.3 presents the results of the activity time-use model component. Section 4.4 discusses self-selection effects, and Section 4.5 focuses on likelihood-based measures of data fit.

\subsection{Residential Location Choice Model Component Results}

Table 2 presents the estimation results for the residential location choice component of the joint model. The first set of variables in Table 2 corresponds to zonal size and density measures. The coefficient on the logarithm of number of households in the zone has the expected positive sign, indicating that individuals are more likely to locate in zones with a large number of housing opportunities. The parameter on this variable is between 0 and 1 , as should theoretically be the case on the size measure (see Bhat et al., 1998 and Daly, 1982). The household density effects indicate that individuals from households with seniors (of age $>65$ years) and young children (of age $\leq 15$ years) prefer low density neighborhoods. The latter result may be a reflection of the "urban-to-suburban flight" trend of households that have young children, as has been documented in several sociological studies (Birch, 2005, Lee and Guest, 1983, Marans, 1979, and Waddell and Nourzad, 2002). This flight trend has been attributed to the safety and neighborhood quality related preferences of households having children. The employment density coefficients indicate that low income individuals (annual household income $<\$ 35,000$ ) and African-American households tend to reside in areas with high employment density, while Caucasians and those who have children (of age $\leq 15$ years) in their household prefer areas of low employment density.

The zonal land-use structure variable effects indicate that individuals shy away from zones with a high fraction of commercial land area and with good land use-mix diversity. The effect of the land-use mix variable is interesting, and suggests that individuals do, in general, prefer zones with homogenous land-use for their home location. This finding may also be an artifact of zone definition strategies, which segregate a study area into traffic analysis zones that are usually defined based on homogeneity of land uses. Thus, the likelihood of a household 
being located in a homogenous land-use zone may be higher than that in a mixed land-use zone simply because most of the residential zones are homogeneous in their land-use.

Our results did not indicate any statistically significant effects of the regional accessibility measures. The zonal demographic variables show strong effects on residential choice. The effects of the next three zonal demographic variables, "absolute difference between zonal median income and household income", "absolute difference between zonal average household size and household size", and "fraction of senior population interacted with presence of senior adults in the household" provide an indication of residential clustering of individuals based on household income levels, and household life cycle stage (defined by household size, and presence of senile adults). Such clustering trends have long been documented in the residential analysis literature (see Waddell, 1993b, and Waddell, 2006). Along similar lines, the zonal race variables, when interacted with individual race, show clear evidence of racial clustering, with the effect being strongest for African-American individuals and weakest for Caucasian individuals. The clustering effect for Asian and Hispanic individuals is somewhere between those for African-Americans and Caucasians, with Asians having a higher tendency to cluster than Hispanics. The racial clustering may be a result of race-specific social networking and/or race-specific preferences for unobserved zonal characteristics. Overall, the clustering effects based on zonal demographics and race composition variables indicate a self-selection process that occurs in the housing market based on income, race, and household life cycle stage (defined by household size, and presence of senile adults).

The last two items in the zonal demographic variables are: (1) the zonal-level average housing cost variable, and (2) the residual obtained from regressing the zonal-level average housing cost variable on zonal bicycling facility density, fraction of commercial land-use, and the fraction of households with income in the highest quartile. The role of the residual variable is to control for the endogeneity of the housing cost variable in residential location choice model component. ${ }^{11}$ After controlling for the endogeneity, the coefficient on the average housing cost variable turned out to be negative and statistically significant indicating that zones with expensive housing are less likely to be chosen.

The next set of variables in Table 2 represents the opportunities offered by a zone for different types of activities. The positive coefficient on the number of schools in a zone, although marginally significant, indicates that households are more likely to locate in zones with better schooling opportunities. Interestingly, we did not find any statistically significant variation in the effect of number of schools based on the presence (or number) of children in the household. This is, in part, because a high fraction of individuals in our sample have children in their households, leading to inadequate variation in the children-related variables. The next variable, "number of physically active recreation centers such as fitness centers/gymnasiums, sports centers, dance and yoga centers", suggests a positive impact of the zonal level opportunities for physically active recreational activity pursuits on a household's preference to reside in that zone.

\footnotetext{
${ }^{11}$ By including the residual variable, we are following the two-stage residual inclusion method (as opposed to the two-stage predictor substitution method) to control for the endogeneity of housing cost with residential location preferences. The reader is referred to Terza et al. (2008) for a detailed discussion of why the two stage residual inclusion method provides consistent estimates in non-linear models, while the two stage predictor substitution method does not. In our analysis, when the residual variable was not included, the housing cost variable was associated with a small t-statistic. However, after correcting for the endogeneity through the two-stage residual inclusion method, the coefficient on the housing cost variable turned out to be statistically significant. The reader is referred to Guevara and Ben-Akiva, 2006, and de Palma et al. (2005) for detailed discussions on the endogeneity of housing price in residential location choice models.
} 
The final variable under zonal activity opportunities indicates the preference of individuals with bicycles in their households to locate in zones with a higher number of natural recreation opportunities, perhaps due to the generally outdoor activity inclination of individuals with bicycles. Admittedly, this variable does not have a highly statistically significant impact on residential choice, but it is included so that its effects can be explored more carefully in future residential choice studies that use a finer neighborhood-level scale for measuring activity opportunity attributes (rather than the aggregate zone-level scale in the current study).

The effects of the zonal transportation network measures show that individuals with seniors (age $>65$ years) in their household are likely to stay away from zones with high highway density. This is possibly a reflection of the preference for relatively quiet, retirement-like, communities amongst households with seniors (though this effect is not very statistically significant). The influence of street block density lends reinforcement to the stereotype of high income households choosing to (or self-selecting to) locate in suburban-like, low density, sprawling, communities away from the "inner city" neighborhoods. Finally, in the set of zonal network measures, the results show that, without exception, households prefer zones with high bicycling facility density, though this effect is particularly strong among individuals from households with several bicycles. Bicycling facilities represent access to certain types of activities such as out-of-home physically active pure recreational travel pursuits (such as bicycling around in the neighborhood), and individuals from households with more bicycles are likely to be outdoor-oriented and physically active by nature (this point will be discussed in Section 4.3.3). This may be the reason why households with bicycles have a strong preference for zones with high bicycling facilities.

The final set of variables includes the household level commute variables. Among these, the total commute time (by auto) of all commuters in the household serves as a surrogate measure of the overall location of the household vis-à-vis the work locations of the commuters in the household (work locations are assumed to be exogenous). As expected, and as evidenced by the negative coefficient associated with this variable, households tend to locate such that the total commute time is reduced. Further, the standard deviation of the corresponding random coefficient is highly significant indicating considerable population heterogeneity in the sensitivity to total commute time in residential location decisions. The coefficient on the next commute variable, total commute cost of all commuters in the household, is negative and statistically significant suggesting that households attempt to reduce their commute costs in their residential location decisions.

The next section discusses the results of the activity time-use model component. Specifically, the various demographic, land-use and other factors that influence individuals' activity time-use preferences are discussed. Further, the results are related to the findings from the residential location choice model component discussed in the current section to draw inferences on the effects of residential self-selection in the time-use model.

\subsection{Time-use Analysis Component Results}

The final specification results of the activity time-use component of the joint model (i.e., the MDCEV modeling component) are presented in Table 3. Each row corresponds to a parameter or a variable, and each column corresponds to a specific activity purpose category. The maintenance activity purpose serves as the base category for all variables. In addition, a blank (i.e., no parameter estimate) for a variable for an alternative implies that the alternative also constitutes the base category for that variable. If the effect of a variable on the preferences of 
multiple activity type categories is not statistically different, then the corresponding parameters were restricted to be equal. Such parameters appear as identical estimates (with identical tstatistics) across the corresponding activity type columns.

\subsubsection{Baseline Preference Constants}

The baseline preference constants (see first row of Table 3) do not have any substantive interpretations. They capture generic tendencies to participate in each discretionary activity type category as well as accommodate the range of continuous independent variables in the model. However, all the baseline preference constants are negative, which is a reflection of the fact that all individuals participate in maintenance activity (the "outside" good), while this is not the case for the remaining discretionary activity purposes.

\subsubsection{Satiation/Translation Parameters}

The satiation parameter estimate of $\alpha_{1}$ for the maintenance activity (i.e., the outside good) alternative is 0.253 , with a t-statistic value of 24.82 for the null hypothesis that $\alpha_{1}=1$. This indicates the presence of strong satiation effects in the time investment on maintenance activities. That is, the marginal utility of time investment in maintenance activity drops rapidly with increasing maintenance time.

The translation parameters $\left(\gamma_{k}\right)$ for the discretionary activity purposes are presented in the second row of Table 3. As discussed in Section 2.1.2, the $\gamma_{k}$ parameters allow corner solutions (i.e., zero time investment in the discretionary activity purposes) as well as serve as satiation parameters. The magnitude of the $\gamma_{k}$ parameter for any activity purpose $k$ is inversely associated with satiation for that activity purpose. Thus, a value closer to zero for activity purpose $k$, in general, implies higher satiation for activity purpose $k$ (and, therefore, lower time investment in activity purpose $k$ ), while a high value for an activity purpose implies lower satiation for that activity purpose (or, equivalently, higher time investment in that activity purpose). The results show high satiation effects (low durations) for time investments in out-ofhome $(\mathrm{OH})$ shopping, $\mathrm{OH}$ meals, $\mathrm{OH}$ physically activity pure recreation, and $\mathrm{OH}$ physically inactive pure recreation. On the other hand, the results indicate the low satiation effects (high durations) for time investments in in-home (IH) relaxation and $\mathrm{IH}$ recreation. The satiation effects for the remaining activities are between these two extremes. These results are consistent with intuitive expectations.

\subsubsection{Household Sociodemographics}

Among the household sociodemographic variables, the effect of household structure on the baseline utilities indicates that individuals living alone are more likely to partake in IH socializing, and less likely to participate in IH relaxing, compared to individuals not living alone. This is perhaps a reflection of the higher need to socialize and interact with other individuals when living alone (see Yamamoto and Kitamura, 1999 for similar results). The specific preference for in-home social activities over out-of-home social activities among individuals living alone is interesting, and needs further exploration in future studies.

The race variable effects show that Caucasians have a higher baseline preference for $\mathrm{OH}$ meal activity relative to other races. Other than this, there are no statistically significant differences among races in time use patterns. This is in contrast to studies of weekend activity time-use that show that Caucasians are not only more likely than non-Caucasians to participate in 
$\mathrm{OH}$ meal activity, but also in all other kinds of $\mathrm{OH}$ recreational activities (see Kapur and Bhat, 2007; and Bhat et al., 2006). This points to greater heterogeneity in time-use among races during the weekends relative to weekdays. The next household sociodemographic attribute is the availability of internet at home, which, as expected, is associated with a higher tendency of individuals to invest time on internet use.

Household income also impacts time investment patterns in activity purposes. Specifically, individuals in low income households have a higher baseline preference for inhome relaxing and in-home recreation relative to individuals in middle and high income households, while those in middle and high income households are more likely to participate in out-of-home meals and out-of-home recreation pursuits. These results are consistent with the higher consumption potential of services and out-of-home recreation facilities of individuals in higher income earning households.

Finally, within the set of household sociodemographic variables, the coefficient on the number of motorized vehicles suggests a positive association between high motorized vehicle ownership and an inactive life style (i.e., lower preference for physically active pure recreational travel as well as physically active out-of-home recreational activities). On the other hand, high bicycle ownership is associated with a lower preference for in-home relaxing and a higher preference for physically active pure recreational travel. The latter result is quite reasonable and indicates that individuals from households with more bicycles are likely to be more outdoororiented and more physically active by nature. In Section 4.2, we pointed to the increased likelihood of individuals with high bicycle ownership to locate themselves in zones with good bicycling facilities. Thus, by including the bicycle ownership variable in the time-use model component, we are capturing residential self-selection effects due to bicycle ownership. Specifically, if bicycle ownership were not included in the time-use model component, it would lead to an over-inflated effect of the potential to encourage physically active pure recreation participation by designing neighborhoods with good bicycling facilities (as we found to be the case in our empirical analysis when we removed the bicycle ownership variable from the timeuse model specification). ${ }^{12,13}$ Overall, the results pertaining to vehicle ownership emphasize the

\footnotetext{
${ }^{12}$ There is no directly observed evidence from the survey to indicate that people who own bicycles self-select into residential locations with high bicycling facilities for physically active pure recreational travel. More generally, there is no directly observed evidence in the survey data that says that residential self-selection may occur due to activity time-use preferences. This argument may be extended to all models built using survey data because such data reflect only decision outcomes rather than behavior/decision-processes. However, there is likely to be some reasonable information from sources other than the data (for example, the literature) that can be brought to bear on the model building process. For instance, the hypothesis that people may self-select into neighborhoods based on activity time-use preferences is not at all new to the literature (see, for example, Boarnet, 2004; Bhat and Guo, 2007, TRB-IOM, 2005). Besides, the residential location choice model already controls for several other possible sources of self-selection, including race, income, household life-cycle, housing price, commute variables, and ATE attributes to minimize any confounding effects. Even after controlling for such a large set of residential choice determinants, bicycle ownership shows up as a significant variable in both residential choice and time-use choice model components. Thus, it is not unreasonable to conclude that there is residential self-selection based on time-use preferences and that such self-selection is manifested through the bicycle ownership variable. Of course, if detailed data pertaining to individuals' residential and activity time-use decision-processes and their attitudes were present, the residential self-selection effects could be even more clearly disentangled.

${ }^{13}$ See Pinjari et al. (2007) for a similar finding on residential self selection effects due to bicycle ownership in a commute mode choice model. Other studies that accommodate such self selection effects due to observed factors include, for example, Bagley and Mokhtarian (2002), Bhat and Guo (2007), Cao et al., (2006a), Guo et al, (2007), Handy et al. (2005), Kitamura et al. (1997), Khattak and Rodriguez (2005), and Schwanen and Mokhtarian (2003, 2005b).
} 
transportation-public health connection. That is, our analysis suggests that policies and educational campaigns aimed at reducing motorized vehicle ownership and increasing bicycle ownership not only can lead to traffic congestion alleviation, but can also play an important role in improving public health.

An interesting point is in order here regarding the effects of household sociodemographics. In earlier studies of weekend time-use, the presence and number of children has been found to play an important role in adult time-use decisions. For instance, Bhat et al. (2006) indicate that individuals in households with children have a high baseline preference for out-of-home recreation and pure recreational pursuits, and a lower preference for in-home leisure activities. They attribute these effects to a stronger need to have a change from caring for children in-home and the propensity to participate with young children in outdoor pursuits. In contrast, we did not find any statistically significant effect of children on time-use patterns on weekdays. This is perhaps because of weekday work- and school-related activities, because of which there is less of a need to have a change from caring for children in-home and less opportunity for joint participation between adults and children.

\subsubsection{Individual Sociodemographics and Employment Characteristics}

Among the individual sociodemographics, the coefficient on the male dummy variable highlights the role of gender in weekday discretionary time-use. Women are more inclined to participate in volunteering activities, while men participate more in internet use, in-home relaxing, in-home recreation, out-of-home meals, and $\mathrm{OH}$ physically active recreation. The higher participation of men in relaxing/meal/recreational pursuits also implies, because of the fixed time constraint across all discretionary and maintenance activities, that men participate less in maintenance activity. That is, women have more responsibility for household maintenance activity, a result consistent with the findings of several earlier studies (see, for example, Chen and Mokhtarian, 2006, Gossen and Purvis, 2005, Goulias, 2002, Levinson, 1999, and Srinivasan, 2004).

Several different functional form specifications were attempted for the age-related variables, including a continuous variable, spline variables that allow piece-wise linear effects of age, and age dummy variables. After extensive testing, the best results were obtained using dummy variables for age less than 30 years, age between 30-65 years, and age greater than 65 years. The age variables are introduced in Table 3 with the age category between 30 to 65 years as the base. The results show that young adults (16-29 years) are more likely than other adults to participate in internet browsing and in all discretionary activities other than $\mathrm{OH}$ volunteering, $\mathrm{OH}$ shopping and physically active recreational pursuits (see Yamamoto and Kitamura, 1999 and Bhat et al., 2006 for similar results). On the other hand, older adults (> 65 years) have a higher baseline preference for out-of-home volunteering activities.

The individual mobility-related variables indicate that, in general, individuals with a driver's license have a higher preference (than those without a driver's license) to participate in out-of-home discretionary activities, while those who are physically challenged are less inclined to participate in physically active activities and pure recreational travel. These are clearly manifestations of enhanced mobility to access activities (in the case of having a driver's license) and physical activity-related constraints (in the case of being physically challenged).

The effect of employment can be discerned from the coefficients on the employment dummy and work duration variables in Table 3. Overall, employed individuals have a lower baseline preference (relative to unemployed individuals) for all in-home activities other than relaxing. They also have a higher preference for $\mathrm{IH}$ relaxing, $\mathrm{OH}$ meal activities, and a lower 
preference for other $\mathrm{OH}$ activities. Further, among those employed, individuals who work longer have a particularly high preference for IH relaxing and a low preference for $\mathrm{OH}$ discretionary activities. These results reflect time constraints that make employed individuals (particularly those working long hours) spend more of their non-work time on maintenance activities (the base category), in-home relaxation, and out-of-home meals. The last variable in this category, the auto travel time from home to work for those who traveled to work on that day, is a surrogate measure for the expected daily commute duration. As expected, individuals with longer commuting times participate less in physically inactive pure recreational travel pursuits (such as driving around in the neighborhood). However, it is interesting to note that a similar effect is not found in the context of physically active pure recreational travel pursuits (such as walking, bicycling and/jogging around in the neighborhood), suggesting that large commute times need not necessarily deter individuals from re-energizing themselves through physically active pure recreational travel.

\subsubsection{Day of Week and Seasonal Variables}

The day of week effects reveal the higher inclination of individuals to participate on Fridays (relative to other weekdays) in such discretionary activities as $\mathrm{OH}$ shopping, socializing (inhome as well as out-of-home), $\mathrm{IH}$ relaxing, $\mathrm{IH}$ recreation, $\mathrm{OH}$ meals, and $\mathrm{OH}$ physically inactive recreation. The results also show the lower preference for pure recreation activities during the summer season, and for all kinds of recreation and IH relaxing activities in the Fall. These seasonal variations need further exploration in future studies. Our attempts to include weatherrelated factors (such as rainfall and temperature) were not successful.

\subsubsection{Activity-Travel Environment Attributes}

Among the activity-travel environment attributes, the parameters of the employment density variable indicate that individuals residing in high employment density neighborhoods are more likely to spend their leisure time at home than out-of-home. This may possibly be a reflection of traffic congestion and mobility problems in areas with high employment density that leads to higher in-home discretionary activity participation.

Within the context of employment density effects, note that there is no statistically significant effect on out-of-home recreational travel and activity pursuits (note the blank cells in the last four columns in the row corresponding to the employment density variable). However, when the income effects were omitted from the activity time-use model, employment density showed a marginally significant negative effect on out-of-home recreational travel and activity pursuits. This is an example of a classic case of endogeneity effect due to omitted attributes (income, in this context). To understand this further, recall the finding from Section 4.3.3 that individuals from high income households are more likely to invest discretionary time in out-ofhome recreational travel and activity pursuits. Also, recall from Section 4.2 that these same individuals from high income households self-select to locate in areas with lower employment density. Due to such self-selection effects, zonal employment density and the individual-level out-of-home recreational travel and activity levels in the zones may appear to be associated. Similar effects of residential self-selection were found in the context of the influence of another zonal density variable, street block density, when the income variable (which has an influence on both activity time-use preferences and the residential location preference toward zones of specific street block density) was dropped from the activity time-use model. After including the income variable, however, the street block density variable did not show any influence on 
activity time-use preferences (note that there is no street block density variable in the activity time-use model). ${ }^{14}$

The next set of variables represents the opportunities offered by a zone for various types of activities. Among these, as expected, the eat-out activity center density reveals the higher likelihood of participation in $\mathrm{OH}$ meal activity in areas with several eat-out centers, and the physically inactive recreational activity center density variable indicates a higher likelihood of $\mathrm{OH}$ physically inactive recreation in areas with several physically inactive recreational centers per square mile. The coefficient on the next variable indicates that, individuals who own one or more bicycles, and live in areas with a high intensity of availability of sports/fitness centers, have a higher baseline preference for $\mathrm{OH}$ physically active recreational pursuits. This reflects the interaction effect of owning a bicycle and the presence of sports/fitness centers on $\mathrm{OH}$ physically active participation, perhaps because individuals who own a bicycle are also fitness-conscious.

The next variable corresponds to the zonal-level intensity of bicycling facilities. The positive impact of the bicycling facility density variable on $\mathrm{OH}$ physically active pure recreation suggests that better bicycling facilities do lead to higher participation rates in physically active pursuits such as walking, biking, or jogging. The coefficient on the interaction of the bicycling facility density variable with household vehicle availability indicates that vehicle ownership moderates down the positive impact of bicycling facilities on $\mathrm{OH}$ physically active pure recreation. This finding further adds to the evidence on the association of higher vehicle ownership with physically inactive lifestyles (see Section 4.3.3).

\subsection{Self-Selection Effect due to Unobserved Factors}

In our model specifications, we explored unobserved heterogeneity in the effects of several ATE and commute-related variables in the residential and time-investment model components [corresponding to the $v_{q l}$ and $\eta_{q k l}$ terms in Equation (3)]. ${ }^{15}$ None of these effects turned out to be statistically significant. However, we did find a statistically significant standard deviation of the unobserved component associated with the bicycling facility density variable that was common to both the residential choice component and the $\mathrm{OH}$ physically active recreation baseline utility in the time-investment model component (corresponding to the standard deviation $\sigma_{\omega k l}$ of $\omega_{q k l}$ in Equation 3; see last paragraph of Section 2.1, and Section 2.2). The estimated standard deviation was 0.04 with a t-statistic of 1.83 (this parameter is not shown in Tables 2 or 3 ). The sign corresponding to the bicycling facility density variable in the $\pm \omega_{q k l} z_{q i l}$ term of the time-use component (see Equation 3) was also positive. The implication is that there are unobserved

\footnotetext{
${ }^{14}$ Unlike in the case of individuals with bicycles self-selecting for their residential location into zones with higher bicycling facilities, there may not be a sufficiently strong activity-related reason why high income individuals selfselect into zones with low employment and low street block densities. Thus, in this case, the self-selection effects is probably a classic case of endogeneity due to omitting the income variable based on which individuals self-select into zones of specific employment density and street block density levels. In either case, the self-selection effects can be controlled by the proposed modeling methodology of including common factors that influence residential location and activity time-use choices.

${ }^{15}$ In the context of ATE and commute-related attributes, we first developed the best systematic specification that considered sensitivity variation to the attributes due to observed individual characteristics. Subsequently, we tested the presence of unobserved heterogeneity by employing random parameters on various ATE/commute related attributes in each of the residential location and time-use model components, keeping the coefficient on the cost variable to be fixed (for estimability reasons). We then examined the presence of common random parameters on attributes across residential location and time-use models (corresponding to the $\omega_{q k l}$ terms in Equation 3).
} 
individual factors (such as fitness consciousness that cannot be completely captured by such observed variables as bicycle ownership) that make individuals locate in areas with good bicycling facilities and also lead to a high preference for physically active recreation. That is, people who are predisposed to physically active lifestyles tend to self-select themselves into zones with very good bicycling facility density for their residence. If this residential selfselection is not accounted for, and the time investment model includes the bicycling facility density variable, the result could be a spurious finding that bicycling facility density causes higher participation levels in $\mathrm{OH}$ physically active recreation. In our model accommodating selfselection, the impact of bicycling facility density on the $\mathrm{OH}$ physically active recreation category was statistically insignificant (see the blank cell corresponding to the $\mathrm{OH}$ physically active recreation column for the bicycling facility density variable in Table 3). However, when we estimated an independent time-investment model without considering self-selection, the coefficient on bicycling facility density corresponding to the $\mathrm{OH}$ physically active recreation activity purpose was positive and highly significant. Clearly, this highlights the need to control for residential self-selection effects for appropriately estimating the effects of the activity-travel environment on activity-travel choices. More generally, it is important to model residential location choice and activity time-use choices in a joint framework to obtain the "true" effects of ATE attributes on activity time-use choices.

\subsection{Overall Likelihood-based Measures of Fit}

The log-likelihood value at convergence for the final joint multinomial logit (MNL)-multiple discrete-continuous extreme value (MDCEV) model is -42106.99. The corresponding value for the independent MNL and MDCEV models with no allowance for residential self selection due to unobserved decision-maker attributes is -42108.51 . The likelihood ratio index for testing the presence of residential self selection due to unobserved factors is 3.04, which is larger than the critical chi-square value with 1 degree of freedom at a $90 \%$ level of significance (the 1 degree of freedom corresponds to the standard deviation of the common error component related to the coefficient on bicycling facility density variable, as discussed in Section 4.4). Although the joint model shows a moderate improvement in model fit, it is important to note here that the independent models with no allowance for self-selection effects due to unobserved factors showed a spuriously estimated positive impact of bicycle facility density on individuals' physically active activity preferences (see Section 4.4). Further, the log-likelihood value is -44127.17 for the independent MNL and MDCEV model system with (a) equal probability for each of the 236 spatial alternatives in the residential location MNL model and (b) only constants in the baseline preference terms, and the satiation and translation terms, in the activity time-use MDCEV model. The likelihood ratio index for testing the presence of exogenous variable effects and residential self selection effects is 4040.36 , which is substantially larger than the critical chisquare value with 92 degrees of freedom at any reasonable level of significance. This clearly underscores the value of the model estimated in this paper to predict residential location and time-use choices of individuals as a function of relevant exogenous variables and accommodating residential self-selection effects.

\section{DEMONSTRATION OF MODEL APPLICATION}

The estimates of the activity time-use component of the joint model system can be applied to predict the changes in time-use patterns due to changes in sociodemographic characteristics and ATE attributes. In this section, we illustrate the application of the model by studying the effects 
on aggregate time-use patterns of changes in two sociodemographic characteristics and two ATE attributes. The sociodemographic changes correspond to a decrease in household vehicle ownership for each individual by one (except for zero car households whose car ownership level is left unchanged), and an increase in household bicycle ownership for each individual by one. The ATE attribute changes include a ten-fold increase in physically inactive recreation centers per square mile in each TAZ, and a ten-fold increase in bicycling facility density in each TAZ. To examine the effects of each of these changes, we computed the aggregate change in the percentage time allocated to each activity purpose. ${ }^{16}$

Table 4 presents the results. Several observations may be made from this table. First, in line with the model estimation results, a decrease in vehicle ownership is associated with an increase in percentage of the time allocated to $\mathrm{IH}$ recreation, $\mathrm{OH}$ physically active pure recreation, and $\mathrm{OH}$ physically active recreational activity pursuits (see the first numberedcolumn). The increase in the percentage time allocated to these activities is off-set by a decrease in the percentage time allocated to other activities, including maintenance and IH relaxing. Second, an increase in bicycle ownership is associated with a decrease in the percentage time allocated to $\mathrm{IH}$ relaxing, $\mathrm{OH}$ physically active pure recreation, and $\mathrm{OH}$ physically active recreational activity pursuits. These changes are off-set by an increase in the time allocated to maintenance activities (see the second numbered-column). One may note from these two observations that policies and educational campaigns aimed at reducing motorized vehicle ownership and increasing bicycle ownership not only can lead to traffic congestion alleviation, but can also play an important role in improving public health (as evidenced by the increase in overall time-use in the $\mathrm{OH}$ physically active recreation categories in the table. Third, the time allocation changes in response to the activity-travel environment attribute changes are in line with the model estimation results discussed in Section 4.3.6, and suggest that the activity-travel environment can be engineered to influence activity time-use (see the third and fourth columns). However, the magnitude of the percentage changes in columns three and four indicate that the ability to do so is very limited. Specifically, the changes in activity time-use are highly inelastic to changes in ATE attributes. Fourth, while the percentage changes in activity time-use due to changes in sociodemographics and changes in ATE attributes are not strictly comparable (because the sociodemographic ordinal variables are changed by 1, while the continuous ATE attributes are changed ten-fold), there is an indication that sociodemographics play a far more dominant role in determining activity time-use than do ATE attributes.

\section{CONCLUSIONS}

This study contributes to both the integrated land use-transportation modeling and activity-based analysis literature by presenting a joint model of residential location choice and activity time-use choices. This modeling system considers a comprehensive set of activity-travel environment (ATE) variables and sociodemographic variables as potential determinants of weekday time-use choices. The model formulation takes the form of a joint mixed Multinomial Logit-Multiple Discrete-Continuous Extreme Value (MNL-MDCEV) structure that (a) accommodates differential sensitivity to the ATE attributes due to both observed and unobserved individual and household attributes, and (b) controls for the self selection of individuals into neighborhoods based on observed and unobserved individual-related factors. To our knowledge, the analysis in this paper presents the first instance of the formulation and application of such a unified

\footnotetext{
${ }^{16}$ To keep the constrained optimization-based prediction process manageable (see Bhat, 2005 for the prediction process details), we randomly chose 150 individuals from the estimation sample for the prediction analysis.
} 
econometric methodological framework for jointly modeling (a) residential location choice (an unordered multinomial discrete choice variable), and (b) activity time-use choice (a multivariate discrete-continuous choice variable), while also accounting for observed and unobserved heterogeneity in the choice processes. The joint model system is estimated on a sample of 2793 households and individuals residing in Alameda County in the San Francisco Bay Area.

The model results offer several insights regarding individual time-use choices. First, there are significant observed factors contributing to residential self selection. For instance, individuals from households with more bicycles are associated with a higher preference for physically active pure recreational travel pursuits. These same individuals locate themselves (or self select) into neighborhoods with good bicycling facilities. This leads to a spurious association between individuals' time investment in physically active pure recreational travel and bicycling facilities in their residential neighborhoods. The spurious association can be controlled by including the bicycle ownership variable in the time-use model. Ignoring the effect of bicycle ownership in the time-use model, however, can lead to an inflated estimate of the effect of bicycling facility density on the time invested in physically active pure recreational travel. Similarly, high income households locate in neighborhoods with low employment density and low street block density. Individuals from such high income households also have a preference for out-of-home recreational activities/travel. Although individuals from high income households may not selfselect into low density neighborhoods for out-of-home recreational activity-related reasons, ignoring income effects in activity time-use choices can lead to a spuriously estimated negative effect of employment density and street block density on out-of-home recreational activities/travel. Overall, even if there are no common unobserved factors influencing residential choice and activity time-use choices, the results suggest that it behooves the analyst to estimate an independent residential choice model so that any observed demographic factors impacting the sensitivity to ATE attributes in residential choice can be considered in the time-use model. In this way, one can reduce the possibility of distorted inferences regarding the impact of ATE attributes on time-use choices. Of course, another reason to model both residential choice and time-use choice, even in the absence of common unobserved factors, is the fact that ATE attributes impact both these choices. Thus, policy decisions regarding changes in ATE characteristics have to be evaluated in the context of spatial relocations as well as time-use shifts to obtain a comprehensive picture of the changes due to ATE-related policies. Second, there are unobserved factors that make individuals predisposed to physically active lifestyles as well as self-select themselves into zones with very good bicycling facility density for their residence. Ignoring such unobserved factors resulted, in our current empirical study, in a spuriously estimated positive effect of the bicycling density variable on physically active recreational activity participation. This result highlights the need to control for residential self-selection effects due to unobserved factors when estimating the effects of the activity-travel environment on activity-travel choices. Third, ATE attributes such as employment density, activity opportunity density/intensity, and bicycling facility density have statistically significant impacts on activity time-use decisions even after controlling for residential self-selection effects due to both observed and unobserved factors. However, the extent of the influence of ATE attributes in activity-travel behavior is rather small. On the other hand, sociodemographic characteristics appear to be far more influential in shaping activity time-use behavior than are the ATE attributes. Fourth, our results emphasize the transportation-public health connection. That is, our analysis suggests that policies and educational campaigns aimed at reducing motorized vehicle ownership and increasing bicycle ownership, when combined with better provision of bicycling 
facilities, not only can lead to traffic congestion alleviation, but can also play an important role in improving public health through increased investment of time in physically active pursuits.

To summarize, our results indicate that activity-travel environment attributes are not "completely" exogenous in activity time-use decisions. Households and individuals locate themselves in ATEs that are consistent with their lifestyle preferences, attitudes, and values. In other words, households and individuals make residential location and activity time-use decisions jointly as part of an overall lifestyle package.

The research in the current paper can be extended and enhanced by (1) undertaking the analysis at a more disaggregate spatial level of analysis than traffic analysis zones (though such a move also promises to raise some very important computational challenges), (2) applying the methodology developed in this paper to richer data sets with attitudinal variables that may further enhance our understanding of the relationship of ATE attributes on activity-travel dimensions, and (3) extending the analysis to include work location choice. Further, a better assessment of the ATE impacts may be obtained from analyzing time-use data for longer time frames (such as one week) than for one day.

\section{ACKNOWLEDGEMENTS}

The authors acknowledge the helpful comments of two anonymous reviewers on an earlier version of the paper. Thanks to Lisa Macias for her help in typesetting and formatting this document. The second author would like to acknowledge the support of an International Visiting Research Fellowship and Faculty grant from the University of Sydney. This research was partially funded by Environmental Protection Agency Grant R831837. 


\section{REFERENCES}

Abraham, J.E., Hunt, J.D., 1997. Specification and estimation of nested logit model of home, workplaces, and commuter mode choices by multiple-worker households. Transportation Research Record 1606, 17-24.

Anas, A., 1981. The estimation of multinomial logit models of joint location and travel mode choice from aggregated data. Journal of Regional Science 21(2), 223-242.

Anas, A., 1995. Capitalization of urban travel improvements into residential and commercial real estate: simulations with a unified model of housing, travel mode and shopping choices. Journal of Regional Science 35(3), 351-375.

Anas, A., Duann, L.S., 1985. Dynamic forecasting of travel demand, residential location, and land development: policy simulations with the Chicago area transportation/land-use analysis system. Papers in Regional Science 56(1), 37-58.

Axhausen, K., Gärling, T., 1992. Activity-based approaches to travel analysis: conceptual frameworks, models and research problems. Transport Reviews 12, 324-341.

Bagley, M.N., Mokhtarian, P.L., 2002. The impact of residential neighborhood type on travel behavior: A structural equations modeling approach. Annals of Regional Science 36(2), 279-297.

Ben-Akiva, M., Bowman, J.L., 1998. Integration of an activity-based model system and a residential location model. Urban Studies 35(7), 1131-1153.

Bhat, C.R., 2003. Simulation estimation of mixed discrete choice models using randomized and scrambled halton sequences. Transportation Research Part B 37(9), 837-855.

Bhat, C.R., 2005. A multiple discrete-continuous extreme value model: Formulation and application to discretionary time-use decisions. Transportation Research Part B 39(8), 679-707.

Bhat, C.R., 2008. The multiple discrete-continuous extreme value (MDCEV) model: role of utility function parameters, identification considerations, and model extensions. Transportation Research Part B 42(3), 274-303.

Bhat, C.R., Gossen, R., 2004. A mixed multinomial logit model analysis of weekend recreational episode type choice. Transportation Research Part B 38(9), 767-787.

Bhat, C.R., Guo, J.Y., 2007. A comprehensive analysis of built environment characteristics on household residential choice and auto ownership levels. Transportation Research Part B 41(5), 506-526.

Bhat, C.R., Koppelman, F.S., 1999. A retrospective and prospective survey of time-use research. Transportation 26(2), 119-139.

Bhat, C.R., Misra, R., 1999. Discretionary activity time allocation of individuals between inhome and out-of-home and between weekdays and weekends. Transportation 26(2), 193229.

Bhat, C.R., Govindarajan, A., Pulugurta, V., 1998. Disaggregate attraction-end choice modeling. Transportation Research Record 1645, 60-68. 
Bhat, C.R., Srinivasan, S., Sen, S., 2006. A joint model for the perfect and imperfect substitute goods case: Application to activity time-use decisions. Transportation Research Part B 40(10), 827-850.

Bhat, C.R., Guo, J.Y., Srinivasan, S., Sivakumar, A., 2004. Comprehensive econometric microsimulator for daily activity-travel patterns. Transportation Research Record 1894, 57-66.

Birch, E.L., 2005. Who lives downtown? Brookings Institution Metropolitan Policy Program, November.

Boarnet, M.G., 2004. The Built Environment and Physical Activity: Empirical Methods and Data Resources. University of California, Irvine. Prepared for the Committee on Physical Activity, Health, Transportation, and Land Use.

Boarnet , M.G., Sarmiento, S., 1998. Can land-use policy really affect travel behavior? A study of the link between non-work travel and land-use characteristics. Urban Studies 35(7), 1155-1169.

Cao, X., Mokhtarian, P.L., Handy, S.L., 2005. The impacts of the built environment and residential self-selection on nonwork travel: A seemingly unrelated regression approach. Paper 06-1595 on the Transportation Research Board 85th Annual Meeting CD-ROM. Washington, D.C.

Cao, X., Mokhtarian, P.L., Handy, S.L., 2006a. Examining the impacts of residential selfselection on travel behavior: Methodologies and empirical findings. Research Report UCDITS-RR-06-18, Institute of Transportation Studies, University of California, Davis, November.

Cao, X., Handy, S.L., Mokhtarian, P.L., 2006b. The influences of the built environment and residential self-selection on pedestrian behavior: evidence from Austin, TX. Transportation 33(1), 1-20.

Cervero, R., Duncan, M., 2002. Residential self selection and rail commuting: a nested logit analysis. Working Paper, University of California Transportation Center, Berkeley, CA. http://www.uctc.net/papers/604.pdf

Cervero, R., Duncan, M., 2003. Walking, bicycling, and urban landscapes: Evidence from the San Francisco Bay area. American Journal of Public Health 93(9), 1478-1483.

Chatman, D.G., 2005. How the built environment influences non-work travel: theoretical and empirical essays. Ph.D. Dissertation, Urban Planning, University of California, Los Angeles.

Chen, C., Mokhtarian, P.L., 2006. Tradeoffs between time allocations to maintenance activities/travel and discretionary activities/travel. Transportation 33(3), 223-240.

Copperman, R., Bhat, C.R., 2007. An analysis of the determinants of children's weekend physical activity participation. Transportation 34(1), 67-87.

Daly, A., 1982. Estimating choice models containing attraction variables. Transportation Research Part B 16(1), 5-15. 
de Palma, A., Motamedi, K., Picard, N., Waddell, P., 2005. A model of residential location choice with endogenous housing prices and traffic for the Paris region. European Transport 31, 67-82.

Eliasson, J., Mattsson, L., 2000. A Model for integrated analysis of household location and travel choices, Transport Research Part A 34(5), 375-394.

Fotheringham, A.S., 1983. Some theoretical aspects of destination choice and their relevance to production-constrained gravity models. Environment and Planning A 15(8), 1121-1132.

Gliebe, J.P., Koppelman, F.S., 2002. A model of joint activity participation between household members. Transportation 29(1), 40-72.

Golob, T.F., McNally, M.G., 1995. A model of household interactions in activity participation and the derived demand for travel. Presented at the European Institute of Retailing and Service Studies (EIRASS), Conference on Activity-Based Approaches, Eindhoven, The Netherlands, May.

Gossen, R., Purvis, C.L., 2005. Changes in women's travel time expenditures, 1990-2000. Paper presented at the Transportation Research Board Conference on Research on Women's Issues in Transportation, Conference Proceedings No. 35. http://onlinepubs.trb.org/onlinepubs/conf/CP35v2.pdf.

Goulias, K.G., 2002. Multilevel analysis of daily time use and time allocation to activity types accounting for complex covariance structures using correlated random effects. Transportation 29(1), 31-48.

Goulias, K.G., Henson, K.M., 2006. On altruists and egoists in activity participation and travel: who are they and do they live together? Transportation 33(5), 447-462.

Greenwald, M.J., 2003. The road less traveled: new urbanist inducements to travel mode substitution for nonwork trips. Journal of Planning Education and Research 23(1), 39-57.

Greenwald, M.J., Boarnet, M.G., 2001. Built environment as determinant of walking behavior analyzing nonwork pedestrian travel in Portland, Oregon. Transportation Research Record 1780, 33-42.

Guevara, C.A., Ben-Akiva, M.E., 2006. Endogeneity in residential location choice models. Transportation Research Record 1977, 60-66.

Guo, J.Y., Bhat, C.R., Copperman, R.B., 2007. Effect of the built environment on motorized and non-motorized trip making: substitutive, complementary, or synergistic? Transportation Research Record 2010, 1-11.

Hammond, D., 2005. Residential location and commute mode choice. Dissertation submitted in fulfillment of the MSC in Transport and Planning, University of Wales, Cardiff.

Handy, S.L., Clifton, K.J., 2001. Local shopping as a strategy for reducing automobile travel. Transportation 28(4), 317-346.

Handy, S.L., Cao, X., Mokhtarian, P.L., 2005. Correlation or causality between the built environment and travel behavior? Evidence from Northern California. Transportation Research Part D 10(6), 427-444. 
Harvey, A.S., Taylor, M.E., 2000. Activity settings and travel behaviour: a social contact perspective. Transportation 27(1), 53-73.

Jones, P. M., Koppelman, F.S., Orfeuil, J.P., 1990. Activity analysis: state of the art and future directions. In Developments in Dynamic and Activity-Based Approaches to Travel Analysis, 34-55, Gower, Aldershot, England.

Kapur, A., Bhat, C.R., 2007. On modeling adults’ daily time use by activity purpose and accompaniment arrangement. Transportation Research Record 2021, 18-27.

Khattak, A.J., Rodriguez, D., 2005. Travel behavior in neo-traditional neighborhood developments: a case study in USA. Transportation Research Part A 39(6), 481-500.

Kitamura, R., Mokhtarian, P.L., Laidet, L., 1997. A micro-analysis of land use and travel in five neighborhoods in the San Francisco Bay area. Transportation 24(2), 125-158.

Kraan, M., 1996. Time to travel?; a model for the allocation of time and money. Unpublished Ph.D. dissertation, Department of Civil Engineering, University of Twente, The Netherlands.

Krizek, K.J., 2000. Pretest-posttest strategy for researching neighborhood-scale urban form and travel behavior. Transportation Research Record 1722, 48-55.

Krizek, K.J., 2003. Residential relocation and changes in urban travel - does neighborhood-scale urban form matter? Journal of The American Planning Association 69(3), 265-281.

Kurani, K.S., Kitamura, R., 1996. Recent developments and the prospects for modeling household activity schedules. Report prepared for the Los Alamos National Laboratory, Institute of Transportation Studies, University of California, Davis, CA.

Kurani, K.S., Lee-Gosselin, M.E.H., 1996. Synthesis of past activity analysis applications. Presented at the Travel Model Improvement Program (TMIP) conference on activity-based travel forecasting, New Orleans, June 2-5.

Lee, B.A., Guest, A.M., 1983. Determinants of neighborhood satisfaction: a metropolitan-level analysis. The Sociological Quarterly 24(2), 287-303.

Lerman, S.R., 1976. Location, housing, automobile ownership and mode to work: a joint choice model. Transportation Research Record 610, 6-11.

Levinson, D.M., 1999. Space, money, life-stage, and the allocation of time. Transportation 26(2), 141-171.

Levinson, D., Yerra, B. (2006) Self-organization of surface transportation networks. Transportation Science 40(2), 179-188.

Lu, X., Pas, E.I., 1997. A structural equation model of the relationships among sociodemographics, activity participation and travel behavior. Presented at the 76th Annual Meeting of the Transportation Research Board, Washington, D.C.

Lu, X., Pas, E.I., 1999. Socio-demographics, activity participation and travel behavior. Transportation Research Part A 33(1), 1-18.

Marans, R.W., 1979. The determinants of neighborhood quality. Annual Housing Survey Studies, No. 3, Office of Policy Development and Research, Department of Housing and Urban Development, Washington, D.C. 
Meloni, I., Guala, L., Loddo, A., 2004. Time allocation to discretionary in-home, out-of-home activities and to trips. Transportation 31(1), 69-96.

Meloni, I., Spissu, E., Bez, M., 2007. A model of the dynamic process of time allocation to discretionary activities. Transportation Science 41(1), 15-28.

MORPACE International, Inc., 2002. Bay area travel survey final report, March 2002. ftp:/ftp.abag.ca.gov/pub/mtc/planning/BATS/BATS2000/

Pas, E.I., 1996. Time and travel demand analysis and forecasting: theory, data collection and modeling. Presented at the Conference on Theoretical Foundations of Travel Choice Modeling, Stockholm, Sweden, August 7-11.

Pas, E.I., Harvey, A.S., 1997. Time use research and travel demand analysis and modeling. In P. Stopher and M. Lee-Gosselin (eds), Understanding Travel Behavior in an Era of Change, 315-338, Elsevier Science Ltd., Oxford.

Pinjari, A.R., Pendyala, R.M., Bhat, C.R., Waddell, P.A., 2007. Modeling residential sorting effects to understand the impact of the built environment on commute mode choice. Transportation 34(5), 557-573.

Salon, D., 2006. Cars and the City: An investigation of transportation and residential location choices in New York City. Dissertation, Department of Agricultural and Resource Economics, University of California, Davis.

Schwanen, T., Mokhtarian, P.L., 2003. Does dissonance between desired and current neighborhood type affect individual travel behaviour? An empirical assessment from the San Francisco Bay Area. Proceedings of the European Transport Conference (ETC), October 8-10, 2003, Strasbourg, France.

Schwanen, T., Mokhtarian, P.L., 2005a. What if you live in the wrong neighborhood? The impact of residential neighborhood type dissonance on distance traveled. Transportation Research Part D 10(2), 127-151.

Schwanen, T., Mokhtarian, P.L., 2005b. What affects commute mode choice: Neighborhood physical structure or preferences toward neighborhoods? Journal of Transport Geography 13(1), 83-99.

Sener, I.N., Bhat, C.R., 2007. An analysis of the social context of children's weekend discretionary activity participation. Transportation 34(6), 697-721.

Srinivasan, S., 2004. Modeling household interactions in daily activity generation. Ph.D. Dissertation, Department of Civil, Environmental and Architectural Engineering, The University of Texas at Austin.

Snellen, D., Borgers, A., Timmermans, H., (2002) Urban form, road network type, and mode choice for frequently conducted activities: a multilevel analysis using quasi-experimental design data. Environment and Planning A, 34(7), 1207-1220.

Terza, J.V., Basu, A., Rathouz, P.J., (2008) Two-stage residual inclusion estimation: addressing endogeneity in health econometric modeling. Journal of Health Economics 27(3), 531-543.

TRB-IOM (Transportation Research Board and Institute of Medicine), 2005. Does the built environment influence physical activity? Special Report 282. 
Vovsha, P., Bradley, M., 2005. Advanced activity-based models in a context of planning decisions. Transportation Research Record 1981, 34-41.

Waddell, P., 1993a. Exogenous workplace choice in residential location models: is the assumption valid in a multinodal metropolis? Geographical Analysis 25(1), 65-82.

Waddell, P., 1993b. A multinomial logit model of race and urban structure. Urban Geography 13(2), 127-141.

Waddell, P., 2001. Towards a behavioral integration of land use and transportation modeling. In D. Hensher (ed.), Travel Behavior Research: The Leading Edge, 65-95, Pergamon, New York.

Waddell, P., 2006. Accessibility and residential location: the interaction of workplace, housing tenure, residential mobility and location choices. Forthcoming in J. Preston, F. Pagliara, and D. Simmonds (eds.) Modelling Residential Location Choice, Ashgate.

Waddell, P., Nourzad, F., 2002. Incorporating non-motorized mode and neighborhood accessibility in an integrated land use and transportation model system. Transportation Research Record 1805, 119-127.

Yamamoto, T., Kitamura, R., 1999. An analysis of time allocation to in-home and out-of-home discretionary activities across working days and non- working days. Transportation 29(2), 231-250.

Ye, X., Pendyala R.M., 2005. A model of daily time use allocation using fractional logit methodology. In H.S. Mahmassani (ed.) Transportation and Traffic Theory: Flow, Dynamics, and Human Interaction, 507-524, Pergamon, Elsevier Science Ltd., Oxford, UK.

Zhang, M., 2006. Travel choice with no alternative: Can land use reduce automobile dependence? Journal of Planning Education and Research 25(3), 311-326. 


\section{LIST OF TABLES}

Table 1.Distribution of Individuals by Number of Discretionary Activity Purposes Participated In Table 2. Estimation Results of the Residential Location Choice Component of the Joint Model Table 3. Estimation Results of the Time-use Component of the Joint Model

Table 4. Impact of Change in ATE Attributes and Sociodemographic Characteristics 
Table 1. Distribution of Individuals by Number of Discretionary Activity Purposes Participated In

\begin{tabular}{|c|c|c|}
\hline $\begin{array}{l}\text { Number of discretionary } \\
\text { activity types participated in }\end{array}$ & $\begin{array}{c}\text { Number of individuals } \\
\text { participated }\end{array}$ & (\%) of individuals participated \\
\hline 0 & 910 & $(32.6 \%)$ \\
\hline 1 & 919 & (32.9\%) \\
\hline 2 & 610 & $(21.8 \%)$ \\
\hline 3 & 241 & $(8.6 \%)$ \\
\hline 4 & 88 & $(3.2 \%)$ \\
\hline 5 & 20 & $(0.7 \%)$ \\
\hline 6 & 5 & $(0.2 \%)$ \\
\hline Total & 2,793 & $100 \%$ \\
\hline
\end{tabular}


Table 2. Estimation Results of the Residential Location Choice Component of the Joint Model

\begin{tabular}{|c|c|c|}
\hline Variables & Parameter & t-stat \\
\hline \multicolumn{3}{|l|}{ Zonal size and density measures (including demographic interactions) } \\
\hline Logarithm of number of households in zone & 0.868 & 17.97 \\
\hline Household density (\#households per acre x $10^{-1}$ ) & 0.000 & fixed \\
\hline Interacted with presence of seniors in household & -0.649 & -5.77 \\
\hline Interacted with presence of children (of age $<5$ years) in household & -0.388 & -2.19 \\
\hline Interacted with presence of children (of age 5 to 15 years) in household & -0.215 & -2.11 \\
\hline Employment density (\#jobs per acre x $10^{-1}$ ) & 0.000 & fixed \\
\hline Interacted with household income less than $\$ 35,000$ per annum & 0.014 & 1.00 \\
\hline Interacted with household belonging to the African American race & 0.111 & 1.76 \\
\hline Interacted with household belonging to the Caucasian race & -0.068 & -1.52 \\
\hline Interacted with presence of children (age $<16$ years) in household & -0.075 & -1.97 \\
\hline \multicolumn{3}{|l|}{ Zonal land-use structure variables (including demographic interactions) } \\
\hline Fraction of commercial land area & -0.384 & -2.20 \\
\hline Land-use mix & -0.268 & -2.40 \\
\hline \multicolumn{3}{|l|}{ Zonal demographics (including demographic interactions) } \\
\hline Absolute difference between zonal median income and household income $\left(\$ \times 10^{-3}\right)$ & -0.023 & -15.37 \\
\hline Absolute difference between zonal average household size and household size & -0.405 & -6.80 \\
\hline $\begin{array}{l}\text { Fraction of senior (age }>65 \text { ) population interacted with presence of senior adult in } \\
\text { Household }\end{array}$ & 2.875 & 4.71 \\
\hline Average housing cost & -0.089 & -3.22 \\
\hline $\begin{array}{l}\text { Residual from regression of housing value on bicycling facility density, and } \\
\text { fractions of commercial land-use and households w/ income in highest quartile }\end{array}$ & 0.117 & 3.16 \\
\hline \multicolumn{3}{|l|}{ Zonal race composition measures (including demographic interactions) } \\
\hline Fraction of African-American population interacted with African-American dummy & 3.715 & 8.78 \\
\hline Fraction of Asian population interacted with Asian dummy variable & 2.910 & 6.55 \\
\hline Fraction of Caucasian population interacted with Caucasian dummy variable & 2.260 & 14.04 \\
\hline Fraction of Hispanic population interacted with Hispanic dummy variable & 1.633 & 2.33 \\
\hline \multicolumn{3}{|l|}{\begin{tabular}{|l} 
Zonal activity opportunity variables (including demographic interactions) \\
\end{tabular}} \\
\hline Number of schools in the zone & 0.015 & 1.52 \\
\hline $\begin{array}{l}\text { Number of physically active recreation centers such as fitness centers, sports centers, } \\
\text { dance and yoga studios }\end{array}$ & 0.100 & 1.96 \\
\hline $\begin{array}{l}\text { Number of natural recreational centers such as parks, gardens, etc. interacted with } \\
\text { Number of bicycles in the household }\end{array}$ & 0.012 & 1.05 \\
\hline \multicolumn{3}{|l|}{ Zonal transportation network measures (including demographic interactions) } \\
\hline $\begin{array}{l}\text { Highway density (miles of highway per square mile) interacted with presence of } \\
\text { seniors (age }>65 \text { ) in household }\end{array}$ & -0.038 & -1.00 \\
\hline $\begin{array}{l}\text { Street block density (number of blocks per square mile } \times 10^{-1} \text { ) interacted with } \\
\text { household income greater than } \$ 90,000 \text { per annum }\end{array}$ & -0.045 & -3.93 \\
\hline Bicycling facility density (miles of bike lanes per square mile) & 0.037 & 3.92 \\
\hline Interacted with number of bicycles in the household & 0.016 & 3.93 \\
\hline \multicolumn{3}{|l|}{ "Household-level commute variables } \\
\hline Total commute time (by auto) of all commuters in the household (minutes) & -0.030 & -2.35 \\
\hline Standard deviation of the random coefficient (assumed normally distributed) & 0.046 & 8.69 \\
\hline Total commute cost of all commuters in the household & -1.129 & -4.84 \\
\hline
\end{tabular}


Table 3. Estimation Results of the Time-use Component of the Joint Model

\begin{tabular}{|c|c|c|c|c|c|c|c|c|c|c|c|c|}
\hline & $\begin{array}{c}\mathrm{OH} \\
\text { Volunteering } \\
\end{array}$ & $\begin{array}{c}\text { IH } \\
\text { Internet } \\
\text { use } \\
\end{array}$ & $\begin{array}{c}\text { OH } \\
\text { Shopping } \\
\end{array}$ & $\begin{array}{c}\text { IH } \\
\text { Socializing } \\
\end{array}$ & \begin{tabular}{c|} 
OH \\
Socializing \\
\end{tabular} & $\begin{array}{c}\text { IH } \\
\text { Relaxing } \\
\end{array}$ & $\begin{array}{c}\text { IH } \\
\text { Recreation } \\
\end{array}$ & $\begin{array}{c}\text { OH } \\
\text { Meals } \\
\end{array}$ & $\begin{array}{c}\text { OH } \\
\text { Physically } \\
\text { Active Pure } \\
\text { Recreation } \\
\end{array}$ & $\begin{array}{c}\text { OH } \\
\text { Physically } \\
\text { Inactive Pure } \\
\text { Recreation } \\
\end{array}$ & $\begin{array}{c}\text { OH } \\
\text { Physically } \\
\text { Active } \\
\text { Recreation } \\
\end{array}$ & $\begin{array}{c}\text { OH } \\
\text { Physically } \\
\text { Inactive } \\
\text { Recreation } \\
\end{array}$ \\
\hline $\begin{array}{l}\text { Baseline Preference } \\
\text { Constants }\end{array}$ & $\begin{array}{c}-6.733 \\
(-33.81)\end{array}$ & $\begin{array}{l}-9.310 \\
(-16.70)\end{array}$ & $\begin{array}{l}-5.968 \\
(-29.43)\end{array}$ & $\begin{array}{l}-7.844 \\
(-29.17)\end{array}$ & $\begin{array}{l}-6.650 \\
(-39.34)\end{array}$ & $\begin{array}{l}-5.648 \\
(-28.66)\end{array}$ & $\begin{array}{c}-5.645 \\
(-28.93)\end{array}$ & $\begin{array}{l}-7.085 \\
(-28.09)\end{array}$ & $\begin{array}{l}-7.075 \\
(-24.53)\end{array}$ & $\begin{array}{c}-7.079 \\
(-36.14)\end{array}$ & $\begin{array}{l}-7.217 \\
(-26.01)\end{array}$ & $\begin{array}{c}-7.521 \\
(-28.55)\end{array}$ \\
\hline $\begin{array}{l}\text { Translation Parameters } \\
\quad\left(\gamma_{k}\right)\end{array}$ & $\begin{array}{l}147.75 \\
(4.10)\end{array}$ & $\begin{array}{l}138.08 \\
(3.95)\end{array}$ & $\begin{array}{l}27.92 \\
(9.43)\end{array}$ & $\begin{array}{l}144.95 \\
(3.89)\end{array}$ & $\begin{array}{l}100.15 \\
(6.21)\end{array}$ & $\begin{array}{c}251.79 \\
(8.86)\end{array}$ & $\begin{array}{c}262.07 \\
(7.08)\end{array}$ & $\begin{array}{c}42.38 \\
(10.79)\end{array}$ & $\begin{array}{l}42.01 \\
(3.44)\end{array}$ & $\begin{array}{l}36.79 \\
(4.41)\end{array}$ & $\begin{array}{l}111.20 \\
(4.08)\end{array}$ & $\begin{array}{l}127.12 \\
(4.84)\end{array}$ \\
\hline \multicolumn{13}{|c|}{ Household Sociodemographics } \\
\hline Single person family & & & & $\begin{array}{l}0.475 \\
(2.05)\end{array}$ & & $\begin{array}{l}-0.285 \\
(-2.43)\end{array}$ & & & & & & \\
\hline Caucasian & & & & & & & & $\begin{array}{l}0.254 \\
(2.44)\end{array}$ & & & & \\
\hline $\begin{array}{l}\text { Have internet access at } \\
\text { home }\end{array}$ & & $\begin{array}{l}2.399 \\
(4.53)\end{array}$ & & & & & & & & & & \\
\hline $\begin{array}{l}\text { Medium annual household } \\
\text { income (35-90K) }\end{array}$ & & & & & & $\begin{array}{l}-0.365 \\
(-2.69)\end{array}$ & $\begin{array}{l}-0.389 \\
(-2.77)\end{array}$ & $\begin{array}{l}0.336 \\
(2.40)\end{array}$ & $\begin{array}{l}0.210 \\
(1.29)\end{array}$ & $\begin{array}{l}0.210 \\
(1.29)\end{array}$ & $\begin{array}{l}0.210 \\
(1.29)\end{array}$ & $\begin{array}{l}0.210 \\
(1.29)\end{array}$ \\
\hline $\begin{array}{l}\text { High annual household } \\
\text { income (>90K) }\end{array}$ & & & & & & $\begin{array}{l}-0.324 \\
(-2.01)\end{array}$ & $\begin{array}{l}-0.503 \\
(-2.71)\end{array}$ & $\begin{array}{l}0.366 \\
(2.27)\end{array}$ & $\begin{array}{l}0.212 \\
(1.13)\end{array}$ & $\begin{array}{l}0.212 \\
(1.13)\end{array}$ & $\begin{array}{l}0.212 \\
(1.13)\end{array}$ & $\begin{array}{l}0.212 \\
(1.13)\end{array}$ \\
\hline $\begin{array}{l}\text { Number of motorized } \\
\text { vehicles }\end{array}$ & & & & & & & $\begin{array}{l}-0.121 \\
(-1.85)\end{array}$ & & $\begin{array}{l}-0.139 \\
(-1.80)\end{array}$ & & $\begin{array}{l}-0.139 \\
(-1.80)\end{array}$ & \\
\hline Number of bicycles & & & & & & $\begin{array}{l}-0.042 \\
(-1.38)\end{array}$ & & & $\begin{array}{l}0.080 \\
(1.31)\end{array}$ & & & \\
\hline \multicolumn{13}{|c|}{ Individual Sociodemographics and Employment Characteristics } \\
\hline Male & $\begin{array}{l}-0.311 \\
(-1.72)\end{array}$ & $\begin{array}{l}0.387 \\
(1.98)\end{array}$ & & & & $\begin{array}{l}0.332 \\
(3.49)\end{array}$ & $\begin{array}{l}0.360 \\
(3.40)\end{array}$ & $\begin{array}{l}0.305 \\
(3.42)\end{array}$ & & & $\begin{array}{l}0.158 \\
(1.08)\end{array}$ & \\
\hline Age $<30$ yrs & & $\begin{array}{l}0.683 \\
(2.72)\end{array}$ & & $\begin{array}{l}0.678 \\
(2.25)\end{array}$ & $\begin{array}{l}0.921 \\
(5.12)\end{array}$ & $\begin{array}{l}0.275 \\
(2.11)\end{array}$ & $\begin{array}{l}0.541 \\
(3.91)\end{array}$ & $\begin{array}{l}0.518 \\
(4.13)\end{array}$ & & $\begin{array}{c}0.351 \\
(1.20)\end{array}$ & & $\begin{array}{l}0.590 \\
(2.67)\end{array}$ \\
\hline Age $>65$ yrs & $\begin{array}{l}0.659 \\
(3.33)\end{array}$ & & & & & & & & & & & \\
\hline Driver's license & & & $\begin{array}{l}0.522 \\
(3.20)\end{array}$ & & & & & $\begin{array}{l}0.522 \\
(3.20)\end{array}$ & & & $\begin{array}{l}0.522 \\
(3.20)\end{array}$ & $\begin{array}{l}0.522 \\
(3.20)\end{array}$ \\
\hline Physically challenged & & & & & & & & & $\begin{array}{l}-0.609 \\
(-1.19)\end{array}$ & & $\begin{array}{l}-0.609 \\
(-1.19)\end{array}$ & \\
\hline Employed & & $\begin{array}{l}-0.396 \\
(-1.63)\end{array}$ & & $\begin{array}{l}-0.424 \\
(-1.84)\end{array}$ & & & $\begin{array}{l}-0.187 \\
(-1.67)\end{array}$ & $\begin{array}{l}0.416 \\
(3.98)\end{array}$ & & & & \\
\hline $\begin{array}{l}\text { Duration of work/school } \\
\text { activity (in minutes) }\end{array}$ & $\begin{array}{l}-0.161 \\
(-3.88)\end{array}$ & $\begin{array}{l}-0.092 \\
(-1.87)\end{array}$ & $\begin{array}{l}-0.137 \\
(-6.60)\end{array}$ & & $\begin{array}{l}-0.115 \\
(-3.92)\end{array}$ & $\begin{array}{l}0.057 \\
(2.92)\end{array}$ & & & $\begin{array}{l}-0.120 \\
(-2.49)\end{array}$ & & & $\begin{array}{l}-0.095 \\
(-2.93)\end{array}$ \\
\hline Auto travel time to work & & & & & & & & & & $\begin{array}{l}-0.018 \\
(-2.70)\end{array}$ & & \\
\hline
\end{tabular}


Table 3 (continued). Estimation Results of the Time-use Component of the Joint Model

\begin{tabular}{|c|c|c|c|c|c|c|c|c|c|c|c|c|}
\hline & $\begin{array}{c}\text { OH } \\
\text { Volunteering } \\
\end{array}$ & $\begin{array}{c}\text { IH } \\
\text { Internet } \\
\text { use } \\
\end{array}$ & $\begin{array}{c}\text { OH } \\
\text { Shopping } \\
\end{array}$ & $\begin{array}{c}\text { IH } \\
\text { Socializing } \\
\end{array}$ & $\begin{array}{c}\text { OH } \\
\text { Socializing } \\
\end{array}$ & $\begin{array}{c}\text { IH } \\
\text { Relaxing } \\
\end{array}$ & $\begin{array}{c}\text { IH } \\
\text { Recreation } \\
\end{array}$ & $\begin{array}{c}\text { OH } \\
\text { Meals }\end{array}$ & \begin{tabular}{|c|} 
OH \\
Physically \\
Active Pure \\
Recreation \\
\end{tabular} & $\begin{array}{c}\text { OH } \\
\text { Physically } \\
\text { Inactive } \\
\text { Pure } \\
\text { Recreation } \\
\end{array}$ & $\begin{array}{c}\text { OH } \\
\text { Physically } \\
\text { Active } \\
\text { Recreation } \\
\end{array}$ & $\begin{array}{c}\text { OH } \\
\text { Physically } \\
\text { Inactive } \\
\text { Recreation } \\
\end{array}$ \\
\hline \multicolumn{13}{|c|}{ Day of the Week and Seasonal Variables } \\
\hline Friday & & & $\begin{array}{l}0.382 \\
(2.99)\end{array}$ & $\begin{array}{l}0.770 \\
(3.01)\end{array}$ & $\begin{array}{l}0.628 \\
(3.78)\end{array}$ & $\begin{array}{l}0.321 \\
(2.72)\end{array}$ & $\begin{array}{l}0.313 \\
(2.33)\end{array}$ & $\begin{array}{l}0.436 \\
(3.89)\end{array}$ & & & & $\begin{array}{l}0.505 \\
(2.77)\end{array}$ \\
\hline Summer & & & & & & & & & $\begin{array}{l}-0.463 \\
(-2.67)\end{array}$ & $\begin{array}{l}-0.463 \\
(-2.67)\end{array}$ & & \\
\hline Fall & & & & & & $\begin{array}{l}-0.360 \\
(-3.40)\end{array}$ & & & $\begin{array}{l}-0.406 \\
(-2.25)\end{array}$ & $\begin{array}{l}-0.406 \\
(-2.25)\end{array}$ & $\begin{array}{l}-0.274 \\
(-2.21)\end{array}$ & $\begin{array}{l}-0.274 \\
(-2.21)\end{array}$ \\
\hline \multicolumn{13}{|c|}{ Activity-Travel Environment Attributes } \\
\hline $\begin{array}{l}\text { Employment density } \\
\quad\left(\# \text { jobs per acre } \times 10^{-1}\right)\end{array}$ & & $\begin{array}{l}0.010 \\
(1.61)\end{array}$ & & $\begin{array}{l}0.010 \\
(1.61)\end{array}$ & & $\begin{array}{l}0.010 \\
(1.61)\end{array}$ & $\begin{array}{l}0.010 \\
(1.61)\end{array}$ & & & & & \\
\hline $\begin{array}{l}\text { \#eat-out centers per } \\
\text { square mile }\left(\mathrm{x} 10^{-1}\right)\end{array}$ & & & & & & & & $\begin{array}{l}0.030 \\
(2.63)\end{array}$ & & & & \\
\hline $\begin{array}{l}\text { \#physically inactive } \\
\text { recreational centers per } \\
\text { square mile }\left({\left.\mathrm{x} 10^{-1}\right)}\right.\end{array}$ & & & & & & & & & & & & $\begin{array}{l}0.090 \\
(3.19)\end{array}$ \\
\hline $\begin{array}{l}\text { Presence of more than } 4 \\
\text { sports/fitness centers in } \\
\text { the residential zone } \\
\text { interacted with } \\
\text { presence of bicycles in } \\
\text { household }\end{array}$ & & & & & & & & & & & $\begin{array}{l}0.187 \\
(2.85)\end{array}$ & \\
\hline $\begin{array}{l}\text { Bicycling facility density } \\
\text { (miles of bike lanes per } \\
\text { square mile) }\end{array}$ & & & & & & & & & $\begin{array}{l}0.116 \\
(2.47)\end{array}$ & & & \\
\hline $\begin{array}{l}\text { Bicycling facility density } \\
\text { interacted with } \\
\text { \#vehicles/\#adults }\end{array}$ & & & & & & & & & $\begin{array}{l}-0.050 \\
(-1.00)\end{array}$ & & & \\
\hline
\end{tabular}


Table 4. Impact of Change in ATE Attributes and Sociodemographic Characteristics

\begin{tabular}{|c|c|c|c|c|}
\hline & \multicolumn{4}{|c|}{ Aggregate change in the percentage time allocated to each activity purpose } \\
\hline & $\begin{array}{c}\text { Household vehicle } \\
\text { ownership } \\
\text { decreased by } 1\end{array}$ & $\begin{array}{c}\text { Household bicycle } \\
\text { ownership } \\
\text { increased by } 1 \\
\end{array}$ & $\begin{array}{c}\text { Zonal-level } \\
\text { physically inactive } \\
\text { recreation centers } \\
\text { per square mile } \\
\text { increased ten-fold } \\
\end{array}$ & $\begin{array}{c}\text { Zonal-level } \\
\text { bicycling facility } \\
\text { density } \\
\text { increased } \\
\text { ten-fold } \\
\end{array}$ \\
\hline Maintenance & -0.51 & 0.15 & -0.02 & -0.03 \\
\hline OH Volunteering & -0.04 & 0.00 & 0.00 & 0.00 \\
\hline IH internet Use & 0.00 & 0.00 & 0.00 & 0.00 \\
\hline OH Shopping & -0.03 & 0.00 & 0.00 & 0.00 \\
\hline IH Socializing & -0.02 & 0.01 & 0.00 & 0.00 \\
\hline OH Socializing & -0.02 & 0.00 & 0.00 & 0.00 \\
\hline $\mathrm{OH}$ Meals & -0.04 & 0.00 & 0.00 & 0.00 \\
\hline IH Relaxing & -0.07 & -0.27 & 0.00 & 0.00 \\
\hline IH Recreation & 0.56 & 0.01 & 0.00 & 0.00 \\
\hline OH Physically Active Pure Recreation & 0.07 & 0.06 & 0.00 & 0.03 \\
\hline OH Physically Inactive Pure Recreation & -0.01 & 0.00 & 0.00 & 0.00 \\
\hline OH Physically Active Recreation & 0.11 & 0.03 & 0.00 & 0.00 \\
\hline OH Physically Inactive Recreation & 0.00 & 0.01 & 0.02 & 0.00 \\
\hline
\end{tabular}

